Prepared for the U.S. Department of Energy under Contract DE-AC05-76RL01830

\title{
Inflow Characterization for Marine and Hydrokinetic Energy Devices FY-2010 Annual Progress Report
}

\author{
MC Richmond \\ J Thomson \\ $\checkmark$ Durgesh \\ B Polagye
}

January 2011

Pacific Northwest

NATIONAL LABORATORY

Proudly Operated by Battelle Since 1965 


\title{
DISCLAIMER
}

This report was prepared as an account of work sponsored by an agency of the United States Government. Neither the United States Government nor any agency thereof, nor Battelle Memorial Institute, nor any of their employees, makes any warranty, express or implied, or assumes any legal liability or responsibility for the accuracy, completeness, or usefulness of any information, apparatus, product, or process disclosed, or represents that its use would not infringe privately owned rights. Reference herein to any specific commercial product, process, or service by trade name, trademark, manufacturer, or otherwise does not necessarily constitute or imply its endorsement, recommendation, or favoring by the United States Government or any agency thereof, or Battelle Memorial Institute. The views and opinions of authors expressed herein do not necessarily state or reflect those of the United States Government or any agency thereof.

\author{
PACIFIC NORTHWEST NATIONAL LABORATORY \\ operated by \\ BATTELLE \\ for the \\ UNITED STATES DEPARTMENT OF ENERGY \\ under Contract DE-AC05-76RL01830
}

Printed in the United States of America
Available to DOE and DOE contractors from the Office of Scientific and Technical Information,
P.O. Box 62, Oak Ridge, TN 37831-0062;
ph: (865) 576-8401
fax: $(865) 576-5728$
email: reports@adonis.osti.gov

\footnotetext{
Available to the public from the National Technical Information Service, U.S. Department of Commerce, 5285 Port Royal Rd., Springfield, VA 22161 ph: (800) 553-6847 fax: $(703) 605-6900$ email: orders@ntis.fedworld.gov online ordering: http://www.ntis.gov/ordering.htm
}

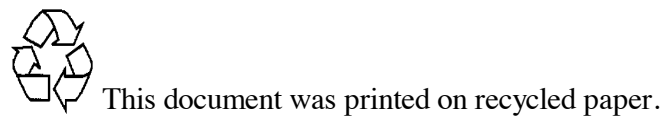




\title{
Inflow Characterization for Marine and Hydrokinetic Energy Devices FY-2010 Annual Progress Report
}

\author{
MC Richmond \\ V Durgesh \\ J Thomson* \\ B Polagye*
}

January 2011

Prepared for

the U.S. Department of Energy

under Contract DE-AC05-76RL01830

Pacific Northwest National Laboratory

Richland, Washington 99352 



\section{Summary}

Marine and Hydro Kinetic devices (MHK) are being widely studied as a source of renewable energy. The Marrowstone Island site is a potential location for installing MHK devices because the tidal currents observed that are sufficient for power generation. In order to quantify the effects of turbulence on MHK devices and the surrounding environment at this site, a preliminary fluid flow field study was conducted here by the Pacific Northwest National Lab (PNNL) in collaboration with the Applied Physics Lab at the University of Washington (APL-UW). This study entailed continuous The Acoustic Doppler Velocimetry (ADV), Acoustic Doppler Current Profiler (ADCP) and Conductivity, Temperature and Depth (CTD) measurements from May 4, 2010 to May 22, 2010, in order to obtain information about turbulence effects during different tidal conditions. The instruments used for collecting the above measurements were deployed at the Marrowstone site using a R/V Jack Robertson provided by the University of Washington (APL-UW). All the measurements were taken at the site with an average depth of $22 \mathrm{~m}$ below the sea surface. ADV acquired velocity data at $32 \mathrm{~Hz}$ sampling frequency at $4.6 \mathrm{~m}$ above the seabed, and ADCP acquired velocity profile data at a sampling frequency of $2 \mathrm{~Hz}$, from a height of $2.6 \mathrm{~m}$ above the seabed to the surface with a bin resolution of $0.5 \mathrm{~m}$. The ADV and ADCP measurements showed that the horizontal velocity had a turbulence intensity of $10 \%$. Furthermore, the spectral analysis from ADV measurements showed that the flow is fully turbulent with $-5 / 3$ slope in the inertial sub-range of the spectra. Moreover, the temporal-frequency analysis showed presence of "eddies" at high frequencies. These preliminary studies provided initial flow field and site characteristics, showed the limitations of the instruments used and highlighted changes that need to be made in the experimental setup for deployment in FY-2011 studies. 



\section{Acknowledgments}

We would like to express our sincere thanks to Joe Talbert for help in design, deployment and recovery of the instrument tripod, Sequoia Scientific for the original upper section of the tripod, and to Andy Jessup for loan of the SBE 37 CTD. We would like to acknowledge Lyle Hibler for reviewing this report and providing helpful comments. 



\section{Abbreviations and Acronyms}

$\begin{array}{ll}\text { ADCP } & \text { Acoustic Doppler Current Profiler } \\ \text { ADV } & \text { Acoustic Doppler Velocimetry } \\ \text { APL-UW } & \text { Applied physics Laboratory at the University of Washington } \\ \text { CTD } & \text { Conductivity, Temperature, and Depth } \\ \text { ENU } & \text { East, North and Up coordinate system } \\ \text { MHK } & \text { Marine and Hydro-Kinetic devices } \\ \text { NREL } & \text { National Renewable Energy Laboratory } \\ \text { QC } & \text { Quality control } \\ \text { R/V } & \text { Research vessel } \\ \text { SNR } & \text { Signal to noise ratio }\end{array}$

\section{Notation}

\begin{tabular}{|c|c|}
\hline$c$ & cut-off correlation \\
\hline$f$ & frequency $(\mathrm{Hz})$ \\
\hline$f_{s}$ & sampling frequency $(\mathrm{Hz})$ \\
\hline$E_{\text {coh }}$ & coherent turbulent kinetic energy $\left(\mathrm{m}^{2} / \mathrm{s}^{2}\right)$ \\
\hline$n$ & Doppler noise (m/s) \\
\hline$S_{u u, A D C P}$ & power spectrum for $\mathrm{u}$ component of velocity from ADCP measurement \\
\hline$S_{v v, A D C P}$ & power spectrum for $\mathrm{v}$ component of velocity from ADCP measurement \\
\hline$S_{w w, A D C P}$ & power spectrum for w component of velocity from ADCP measurement \\
\hline$S_{u u, A D V}$ & power spectrum for $\mathrm{u}$ component of velocity from ADV measurement \\
\hline$S_{v v, A D V}$ & power spectrum for $\mathrm{v}$ component of velocity from ADV measurement \\
\hline$S_{w w, A D V}$ & power spectrum for w component of velocity from ADV measurement \\
\hline$T I$ & turbulent intensity $(\%)$ \\
\hline$T K E$ & turbulent kinetic energy $\left(\mathrm{m}^{2} / \mathrm{s}^{2}\right)$ \\
\hline$u$ & u component of velocity $(\mathrm{m} / \mathrm{s})$ \\
\hline$v$ & v component of velocity $(\mathrm{m} / \mathrm{s})$ \\
\hline$w$ & w component of velocity $(\mathrm{m} / \mathrm{s})$ \\
\hline$u^{\prime}$ & u component of velocity fluctuation $(\mathrm{m} / \mathrm{s})$ \\
\hline$v^{\prime}$ & $\mathrm{v}$ component of velocity fluctuation $(\mathrm{m} / \mathrm{s})$ \\
\hline$w^{\prime}$ & w component of velocity fluctuation $(\mathrm{m} / \mathrm{s})$ \\
\hline$\sigma_{u}$ & standard deviation for $\mathrm{u}$ component of velocity $(\mathrm{m} / \mathrm{s})$ \\
\hline$\sigma_{v}$ & standard deviation for $\mathrm{v}$ component of velocity $(\mathrm{m} / \mathrm{s})$ \\
\hline$\sigma_{w}$ & standard deviation for w component of velocity $(\mathrm{m} / \mathrm{s})$ \\
\hline$\sigma_{u, c}$ & standard deviation for $u$ component of velocity corrected for doppler noise $(\mathrm{m} / \mathrm{s})$ \\
\hline$\sigma_{v, c}$ & standard deviation for $\mathrm{v}$ component of velocity corrected for doppler noise $(\mathrm{m} / \mathrm{s})$ \\
\hline $\begin{array}{l}\sigma_{w, c} \\
\langle.\rangle\end{array}$ & $\begin{array}{l}\text { standard deviation for w component of velocity corrected for doppler noise }(\mathrm{m} / \mathrm{s}) \\
\text { ensemble averaging }\end{array}$ \\
\hline
\end{tabular}





\section{Contents}

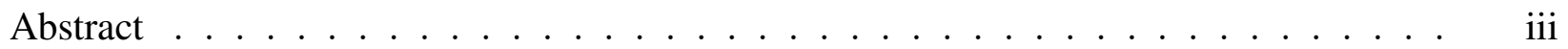

Acknowledgments . . . . . . . . . . . . . . . . . . . v v

Abbreviations and Acronyms ............................... vii

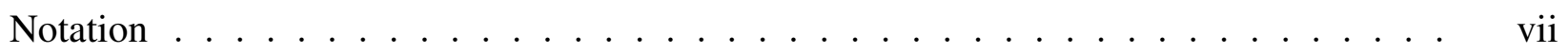

1.0 Introduction . . . . . . . . . . . . . . . . . . . . 1.1

2.0 Study area and deployment . . . . . . . . . . . . . . . . . . . . 2.1

2.1 Acoustic Doppler Velocimetry (ADV) . . . . . . . . . . . . . . 2.1

2.2 Acoustic Doppler Current Profiler (ADCP) . . . . . . . . . . . . . . 2.1

2.3 Conductivity, Temperature and Depth $(\mathrm{CTD}) \ldots \ldots \ldots \ldots$

2.4 Tripod motion $\ldots \ldots \ldots \ldots \ldots \ldots \ldots$

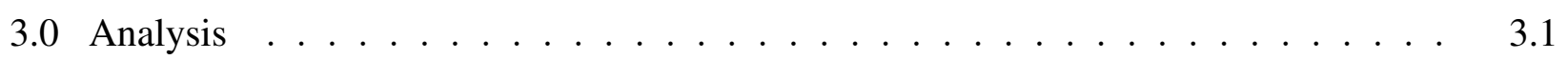

3.1 Data quality control . . . . . . . . . . . . . . . 3.1

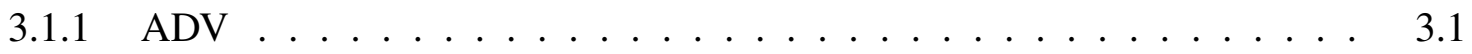

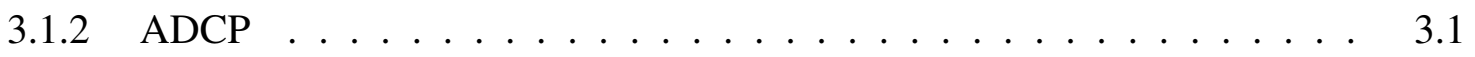

3.2 Mean quantities . . . . . . . . . . . . . . . . . . . 3.3

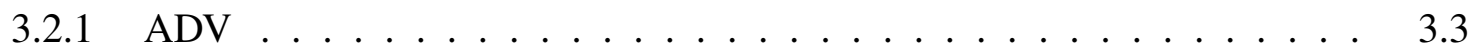

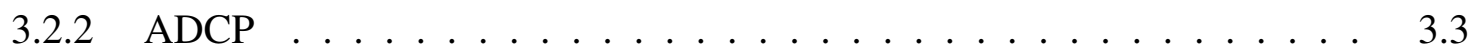

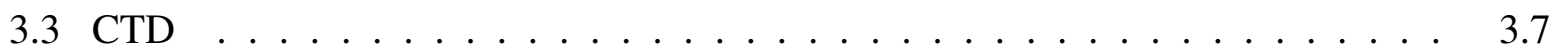

3.4 Turbulence quantities . . . . . . . . . . . . . . . 3.7

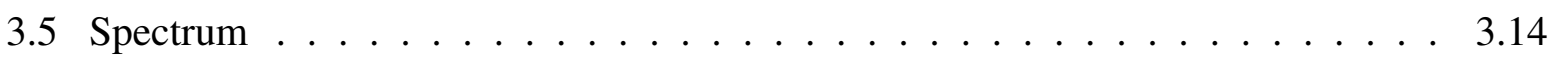

3.6 Length and Time scales . . . . . . . . . . . . . . . . . . 3.14

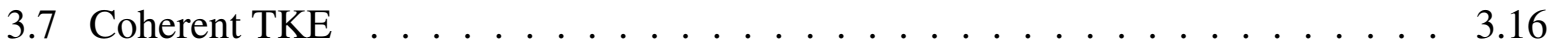




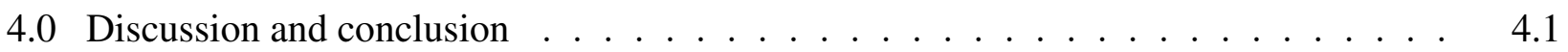

5.0 Future work . . . . . . . . . . . . . . . . . . . . . . . . . 5.1

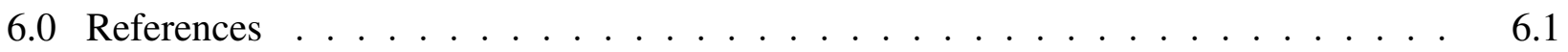

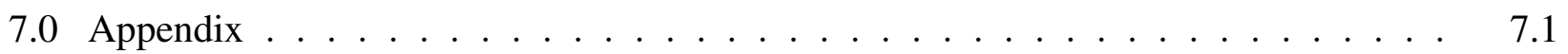




\section{Figures}

2.1 Marrowstone site location for ADV, ADCP and CTD measurement

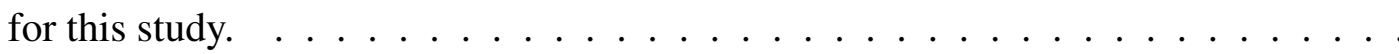

2.2 (a) Tripod, instrument mounts, and ballast prior to deployment from the R/V Jack Robertson (University of Washington Applied Physics Laboratory), and (b) schematic of Tripod with mounts and critical dimensions. . . . . . . . . . . . . . . . . .

2.3 Schematic showing a typical measurement sampling volume and location for ADCP and ADV. . . . . . . . . . . . . . . . . . . 2.4

3.1 Example of quality control on a single ADV burst with 2048 data samples. Top to bottom panel: 1) Acoustic correlation, 2) signal to noise ratio, 3) raw velocity data and crosses showing anomalous data points, and 4) quality controlled velocity data. Colors indicate components of velocity. . . . . . . . . . . . . . . . . . . . . .

3.2 Echo intensity for each acoustic beam from ADCP. . . . . . . . . . . . . . . 3.4

3.3 Mean velocities (instrument coordinate system) for each burst during ADV deployment at Marrowstone Island site.

3.4 Magnitude of mean horizontal velocities (instrument coordinate system) for each burst during ADV deployment at Marrowstone Island site. . . . . . . . . . . . . . . . . . . . . .

3.5 (a) Histogram of the horizontal velocity direction(instrument coordinate system), and (b) horizontal velocity vector with magnitude and direction (instrument coordinate system) . . . . . . . . . . . . . . . . .

3.6 Mean pressure for each burst during ADV deployment at Marrowstone Island site. . . . . . . . . . . . . . . . . . . . . . . . . .

3.7 Mean pressure and mean $u$ component of velocity from ADV measurements for 12th May 2010 to 18th May 2010 . . . . . . . . . . . . . . . . . .

3.8 Velocities along the beam after quality control for ADCP measurements performed at Marrowstone Island site, where solid black line represents the water depth.

3.9 Horizontal velocities magnitude along with flow direction for ADCP measurement performed at Marrowstone Island site, where solid black line represents the water depth 
3.10 Velocity profiles for four different velocity magnitude ranges from ADCP measurements. The range of horizontal velocity magnitude from top to bottom: (1) $0-0.4 \mathrm{~m} / \mathrm{s}$, (2) $0.4-0.8 \mathrm{~m} / \mathrm{s}$, (3) $0.8-1.2 \mathrm{~m} / \mathrm{s}$, and (4) $1.2-1.6 \mathrm{~m} / \mathrm{s}$. Cross marks represent data points used for ensemble averaging. The exponent for the power law fit is approximately

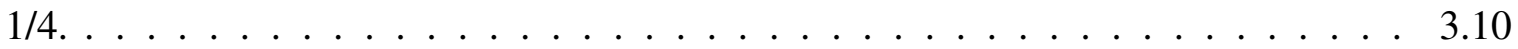

3.11 Histogram of the horizontal velocity direction (ENU coordinates system) for different heights from ADCP measurements: (a) $4.71 \mathrm{~m}$ from seabed, (b) $10.21 \mathrm{~m}$ from seabed, and (c) $15.21 \mathrm{~m}$ from seabed.

3.12 Polar plot of the horizontal velocity (magnitude along with direction(ENU coordinates system)) for different heights from ADCP measurements:

(a) $4.71 \mathrm{~m}$ from seabed, (b) $10.21 \mathrm{~m}$ from seabed, and (c) $15.21 \mathrm{~m}$ from seabed. . . . . . . . . . . . . . . . . . . . . . . . . . .

3.13 CTD measurements at Marrowstone Island site: (a) water depth for entire deployment, (b) salinity of the site for entire deployment, and (c) mean temperature of the site for entire deployment. . . . . . . . . . . . . . 3.12

3.14 Top plot showing mean $u$ component of velocity, middle plot showing corrected standard deviation, and bottom plot showing turbulent intensities from ADV measurements.

3.15 Average TKE for each burst for entire ADV deployment. $\ldots \ldots \ldots$. . . . . . 3.13

3.16 (a) Mean ADV velocity magnitude non-slack velocity shown with blue marker, (b) and (c) show the auto-spectra of velocity components for a single burst, for non-slack and slack condition respectively, (d) and (e) show the ensemble average of auto-spectra of velocity components, for non-slack and slack condition respectively. The commonly observed $f^{-5 / 3}$ shape is shown by the dashed line. . . . . . . . . . . . . 3.17

3.17 Auto-spectral density from ADV and ADCP measurements for nonslack condition.

3.18 Auto-spectral density from ADCP measurements for non-slack condition at different heights $\mathrm{z}=4.21,10.21$ and $15.21 \mathrm{~m} . \ldots \ldots \ldots$

3.19 Auto-correlation function: (a) non-slack tidal condition, and (b) slack tidal condition. . . . . . . . . . . . . . . . . . 
3.20 (a) Coherent Turbulent Kinetic Energy $\left(E_{c o h}\right)$ for a ADV burst, (b) temporal-frequency spectral decomposition of $E_{c o h}$, and (c) Higher frequency component of temporal-frequency spectral decomposition

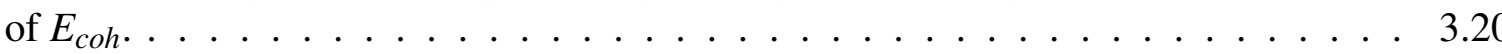

3.21 (a) Coherent Turbulent Kinetic Energy $\left(E_{c o h}\right)$ for a ADV burst, (b) temporal-frequency spectral decomposition of $E_{c o h}$, and (c) Higher frequency component of temporal-frequency spectral decomposition

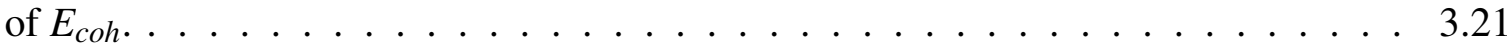

5.1 Schematic of tentative deployment mooring for FY-2011 . . . . . . . . . . . . 5.2 


\section{Tables}

3.1 Summary of horizontal velocity statistic from ADV and ADCP with and without correction for Doppler noise. . . . . . . . . . . . . . 3.12

3.2 Integral length and time scales $\ldots \ldots \ldots \ldots$

5.1 Tentative Experiments to be performed for FY-2011 . . . . . . . . . . . . 5.1

7.1 Sampling design for all the measurements performed for this study. . . . . . . . . . 7.1 


\subsection{Introduction}

Marine and Hydro-Kinetic (MHK) devices are being developed and studied as a renewable source of energy. MHK devices extract energy from tidal currents using underwater turbines; their working principle is very similar to that of wind turbines. Although this technology is still in the nascent stages of development, in the past few years, MHK devices of various designs have been installed at different locations, and are operational too. For optimal power generation from tidal currents using MHK devices, a detailed understanding of the fluid flow field surrounding these devices is essential, as turbulent fluctuations are known to reduce turbine performance and cause material fatigue. This in turn decreases the lifespan of the MHK devices. Similar effects of turbulent fluctuations have been observed in wind turbines as well. Moreover, the quantification of fluid flows around MHK devices is also required for assessing environmental effects of turbulent mixing on water quality and sediment transport at a given site.

The Marrowstone Island site in Washington is an ideal location for installing MHK devices as it has high tidal currents that are essential for energy production. Before installing MHK devices at the Marrowstone Island site, a detailed fluid flow field understanding was required in order to quantify the turbulence at the site, and its effects on the MHK devices. For this purpose, the Pacific Northwest National Laboratory (PNNL), in collaboration with the Applied Physics Laboratory at the University of Washington (APL-UW), has carried out a detailed preliminary fluid flow field study using Acoustic Doppler Velocimetry (ADV) measurements, Acoustic Doppler Current Profiler (ADCP) measurements, and Conductivity, Depth and Temperature (CTD) measurements. These measurements were performed continuously for two weeks, in order to collect data during neap and spring tides, as well as during diurnal tidal variations. The ADV data provided single point velocity measurements close to the base height of the MHK devices while the ADCP data provided the velocity profile from the seabed to the water surface. In addition, the CTD measurements provided salinity, depth and temperature profiles for the site. These measurements collectively provided an insight into the site-specific tidal variations in the flow field as well as in the conditions existing during different tidal cycles. Mean flow field analysis showed a tidal variation in velocity with high turbulent fluctuations while spectrum analysis showed the nature of turbulence at the site. Furthermore, wavelet analysis of the fluid flow field data provided information about the presence of "eddies" even at higher frequencies, which may have a detrimental effect on the performance and structure of the MHK devices. This preliminary fluid flow field study provided an insight into the fluid dynamic properties of the site, which will aid in planning more comprehensive experiments for FY-2011 studies. 



\subsection{Study area and deployment}

For this study, Acoustic Doppler Velocimetry (ADV), Acoustic Doppler Current Profiler (ADCP) and Conductivity,Temperature, and Depth (CTD) measurements were continuously performed at a Nodule Point on the Marrowstone Island $\left(48^{\circ} 01^{\prime} 55.154^{\prime \prime} \mathrm{N}, 122^{\circ} 39^{\prime} 40.326^{\prime \prime} \mathrm{W}\right)$ for two weeks. This site was selected for the study as it is being considered for future deployment of MHK devices. It was necessary to quantify the flow conditions at this site in order to determine the effects of turbulence on the MHK devices and the surrounding environment. For this purpose, all the measurements were performed for two weeks to obtain comprehensive tidal flow data. The site location and bathymetry data are shown in Figures 2.1(a) and (b). Figure 2.2 shows the instrumentation tripod, which was deployed at a depth of $22 \mathrm{~m}$ at the Marrowstone Island site, using the R/V Jack Robertson provided by the University of Washington, Applied Physics Lab. A $1500 \mathrm{lbs}$ ballast was added to the tripod for stability, as shown in the figures. The instrumentation tripod was designed and deployed in such a way that the ADV would be located $4.6 \mathrm{~m}$ above the seabed while the ADCP would be able to collect data from $2.1 \mathrm{~m}$ above the seabed up to the surface.

\subsection{Acoustic Doppler Velocimetry (ADV)}

ADV measurements have been extensively used to quantify turbulence and understand turbulent flows in river, oceans and flumes [Voulgaris and Trowbridge (1997), Garcia et al. (2005), Lane et al. (1998), Thomson et al. (2010)]. For this study, a Nortek vector (6 MHz) ADV was used to collect high temporal resolution data at a single point. A typical schematic of sampling volume for a ADV measurement is shown in Figure 2.3, for this study the ADV sampling volume is less than $0.01 \mathrm{~m}^{3}$. The ADV was setup to acquire $64 \mathrm{~s}$ of data every 10 minutes. This $10 \%$ duty cycle was setup in order to conserve power and memory for two weeks of deployment at the site. At every burst, the ADV recorded data for $64 \mathrm{~s}$ at a sampling frequency of $32 \mathrm{~Hz}$, thereby collecting 2048 data points for every single burst. This sampling scheme was used to capture high-frequency fluctuation of velocity within a burst, with each burst being assumed to be quasistationary.

\subsection{Acoustic Doppler Current Profiler (ADCP)}

RDI Workhorse Sentinel (600 kHz) was used to collect low temporal resolution velocity profile data from the seabed up to the surface. A typical schematic of sampling volume for a ADCP measurement is shown in Figure 2.3. As seen in the figure, the ADCP measurement volume is significantly larger than the ADV sampling volume. The ADCP was setup to acquire data every 30 minutes in order to conserve power and memory for two weeks of deployment. The RDI ADCP recorded data for $64 \mathrm{~s}$ at a sampling frequency of $2 \mathrm{~Hz}$, thereby collecting 128 data points for every single burst. The data were recorded in beam co-ordinates in order to avoid the assumption of homogeneity required in the East-North-Up (ENU) coordinate system transformation. The ADCP recorded data from $2.6 \mathrm{~m}$ above the seabed up to the surface at a bin resolution of $0.5 \mathrm{~m}$. 


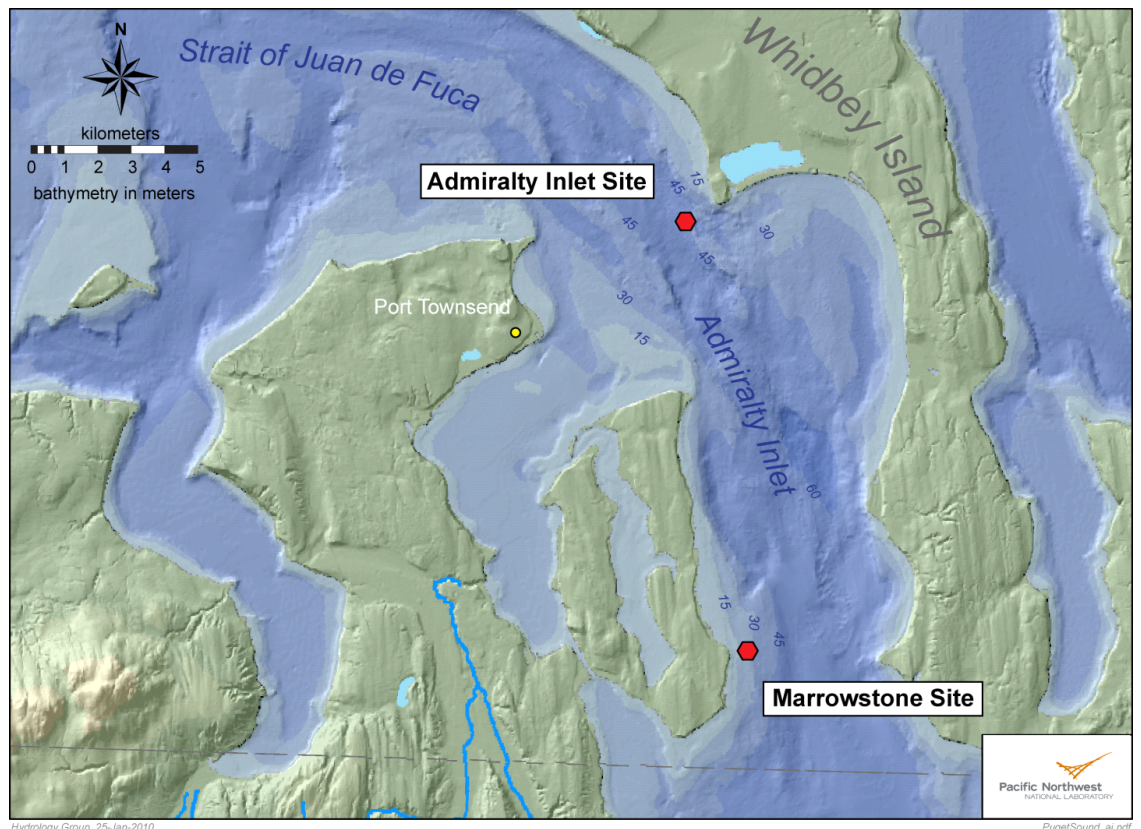

(a) Marrowstone

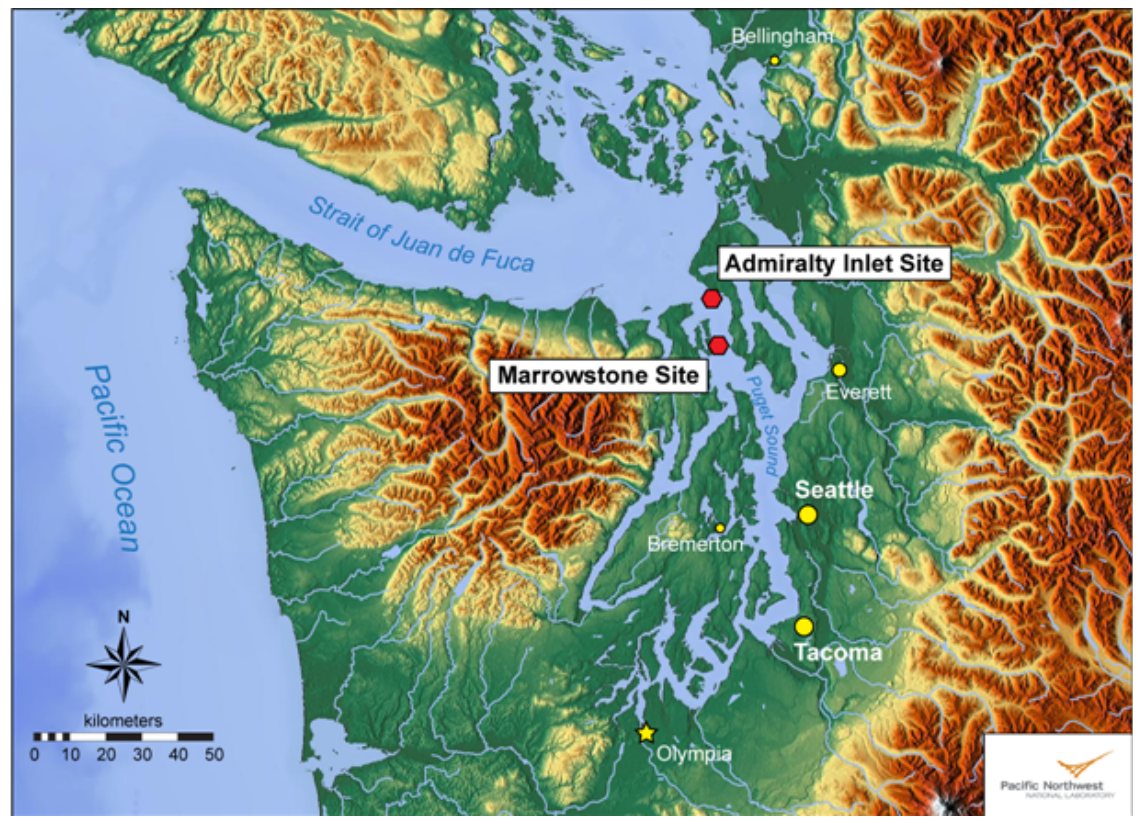

(b) Zoomed out view

Figure 2.1. Marrowstone site location for ADV, ADCP and CTD measurement for this study.

\subsection{Conductivity, Temperature and Depth (CTD)}

In order to understand the flow conditions, conductivity, temperature, and depth (CTD) data were collected using Sea Bird Electronics SBE 37. The CTD instrument acquired data every 30 s over the entire period of deployment. The CTD was attached to the tripod at a depth of $1.12 \mathrm{~m}$ above the seabed, as shown in Figure 2.2(b). 


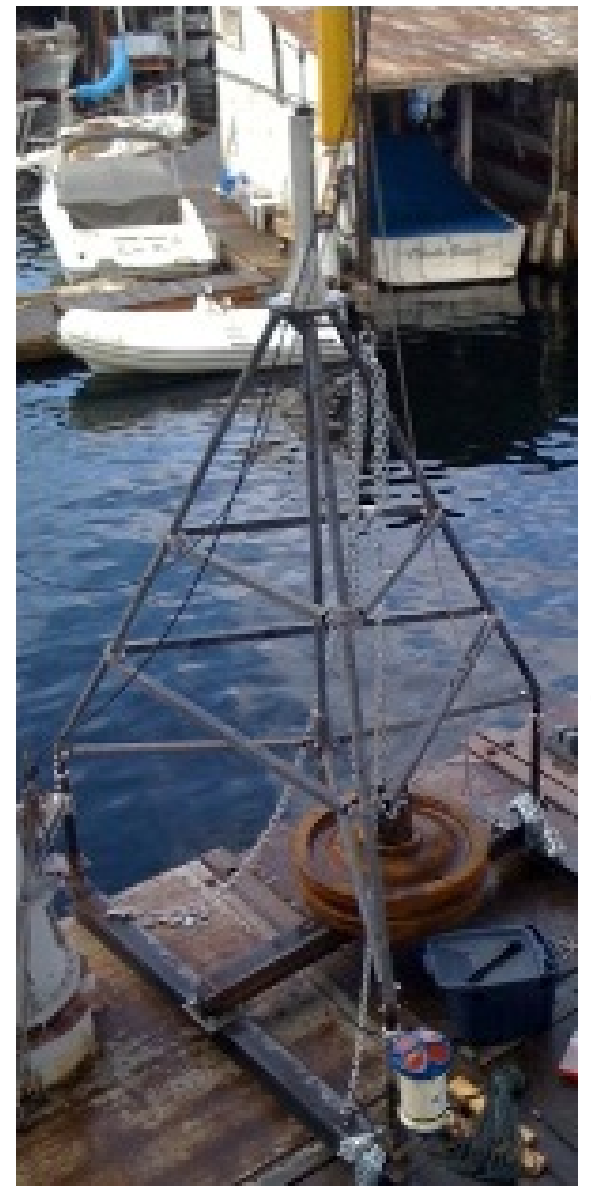

(a) Tripod

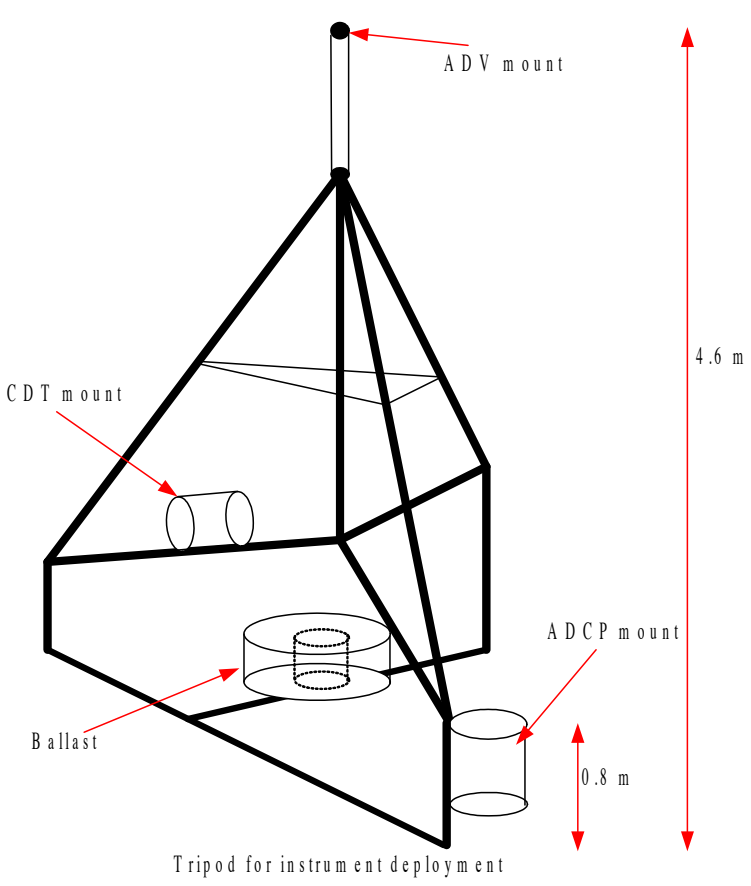

(b) Schematic

Figure 2.2. (a) Tripod, instrument mounts, and ballast prior to deployment from the R/V Jack Robertson (University of Washington Applied Physics Laboratory), and (b) schematic of Tripod with mounts and critical dimensions.

\subsection{Tripod motion}

In order to determine the movement of the tripod during the initial phase of deployment, acceleration data were collected using an HOBO Pendant-G accelerometer. These data were recorded at a sampling frequency of $1 \mathrm{~Hz}$ for the first six hours of the deployment. The raw data showed some correlation with the tidal currents, indicating slight motion of the instruments. However, the acceleration spectra are flat (not shown), suggesting that no strumming or tonal motion, that would require correction of velocity auto-spectra in ADV measurements, was generated. Integrating the accelerations data acquired from the accelerometer suggested horizontal translations of $2 \mathrm{~mm}$, which are typically observed during strong currents. 


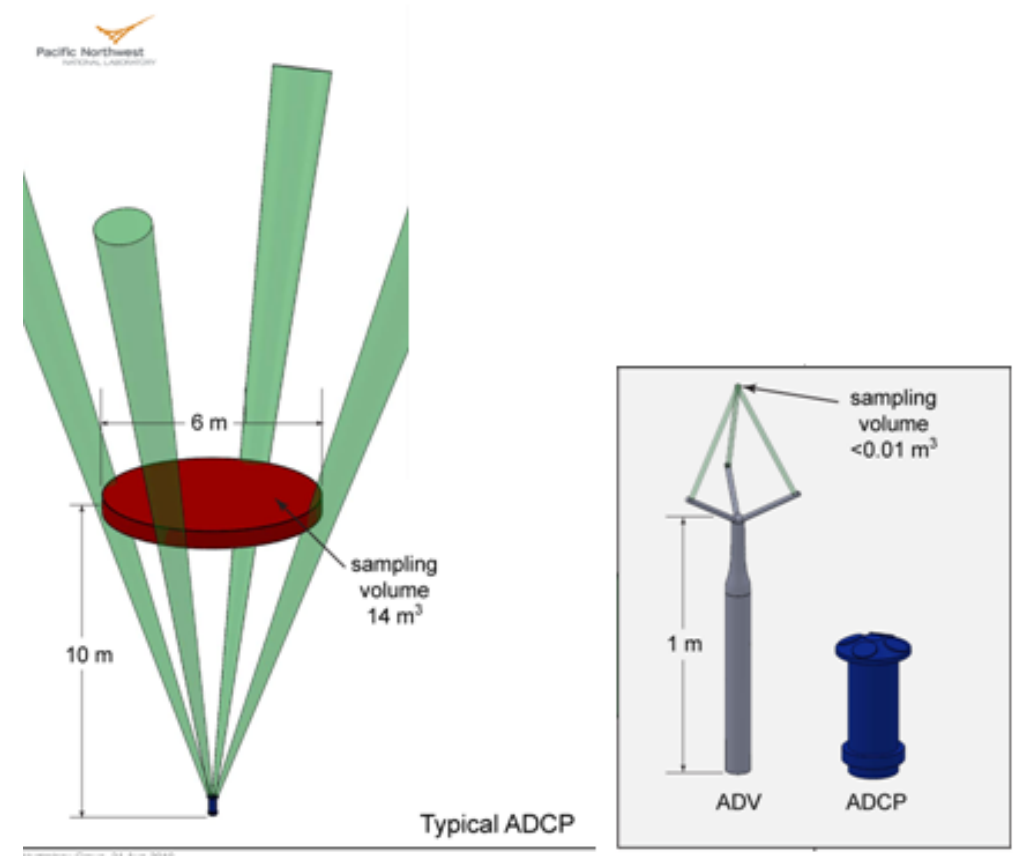

Figure 2.3. Schematic showing a typical measurement sampling volume and location for ADCP and ADV. 


\subsection{Analysis}

\subsection{Data quality control}

\subsubsection{ADV}

The ADV measurements performed at the Marrowstone Island site provided single point high temporal resolution data. Before performing turbulence quantification from the same, these ADV data were subjected to quality control procedures in order to remove noise and spikes caused by spurious data points. The first step in quality control involved removing the data with low correlation and spikes [Goring and Nikora (2002)]. Typically in the ADV measurements, noise is approximately inversely proportional to the square root of the number of pulses per sample, for further detail see references [Elgar and Raubenheimer (2001), Elgar et al. (2005)]. Therefore, in this study, a low correlation cut-off $c$ value [Elgar and Raubenheimer (2001), Elgar et al. (2005)] was determined using the equation

$$
c=30+40 \sqrt{f_{s} / 25},
$$

where $f_{s}$ is the sampling frequency in Hz. The next step was to replace spurious data points with the running mean; it has been shown that interpolation of data along the small gaps between data points replaced by the running mean does not significantly alter the spectra or the second order moments [Elgar and Raubenheimer (2001), Elgar et al. (2005)]. A typical quality control result is shown in Figure 3.1. The topmost plot in the figure shows the acoustic correlation values, and the second plot from the top shows signal to noise ratios, for data points in a single burst. The third plot from the top shows the raw velocity data acquired by ADV where crosses represent the spurious data points that will be replaced by the running mean. The bottommost plot shows the quality controlled data where the spurious data have been replaced with running mean values. It should also be noted that the data acquired from the Nortek ADV has expected random error $n$ (Doppler noise) of $0.04 \mathrm{~m} / \mathrm{s}$ per ping in an ensemble, as specified in the Nortek manual. This doppler noise was later on used to correct the calculated standard deviation in velocity measurements from ADV, using the equation

$$
\sigma_{v, c}=\sqrt{\sigma_{v}^{2}-n^{2}}
$$

where $\sigma_{v, c}$ is the corrected standard deviation, $\sigma_{v}$ is the uncorrected standard deviation, and $n$ is the doppler noise. The corrected standard deviation was also used to calculate the corrected turbulent intensities.

\subsubsection{ADCP}

ADCP provided velocity profile data from the seabed to the surface, at a sampling frequency of $2 \mathrm{~Hz}$. These data were also quality controlled before further analysis. The quality control involved removing bins with low acoustic correlation, bins at or above the surface, and anomalous spikes. Furthermore, the upper four bins were removed because of the contamination of the velocity data due to acoustic reflection from the sea surface. The echo intensity for all four 

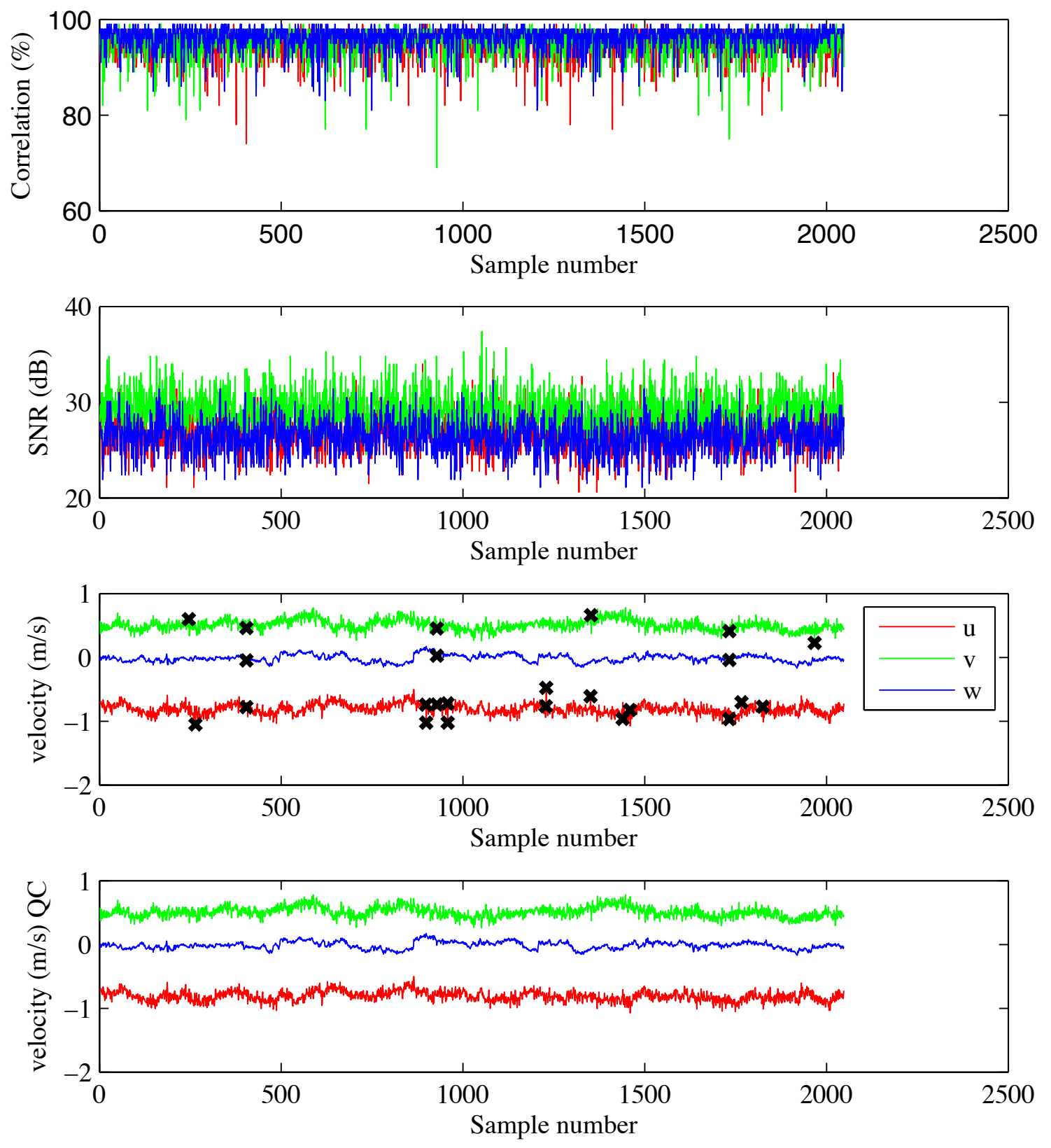

Figure 3.1. Example of quality control on a single ADV burst with 2048 data samples. Top to bottom panel: 1) Acoustic correlation, 2) signal to noise ratio, 3) raw velocity data and crosses showing anomalous data points, and 4) quality controlled velocity data. Colors indicate components of velocity. 
ADCP beams is shown in the Figure 3.2. As shown here, the bins close to the bottom surface had significantly higher acoustic intensities as compared to the other bins, for all four beams. This could be due to either the higher sediment concentration in the water close to the bottom surface, or the acoustic reflection from the sea bottom. Moreover, an abrupt change in the acoustic intensity was also observed close to the air-water interface, as shown in the figure. This change in intensity could be used to identify the water-air interface.

\subsection{Mean quantities}

\subsubsection{ADV}

The ADV measurements were performed at a height of $4.6 \mathrm{~m}$ above the seabed for a period of two weeks at the Marrowstone Island site. The mean velocities from all bursts for ADV measurements, after quality control, are shown in Figure 3.3. As observed in the figure, the velocities show the tidal fluctuations during neap and spring tides as well as during diurnal tidal variations. The mean vertical component of velocities (i. e. $w$ ) is significantly lower than the mean horizontal components of velocities (i. e. $u$ and $v$ ), suggesting no significant mean vertical motion of the water at this depth. The MHK devices are capable of extracting most of the energy from the horizontal velocity components. Therefore, the horizontal velocity magnitudes (i. e. $\sqrt{u^{2}+v^{2}}$ ) for each burst were calculated, and are shown in Figure 3.4. The horizontal velocity magnitudes reach a maximum velocity of $1.5 \mathrm{~m} / \mathrm{s}$, and an average velocity of approximately $1.0 \mathrm{~m} / \mathrm{s}$; these higher values make the Marrowstone Island site a viable location for energy extraction by MHK devices. It is also observed from Figure 3.3 that $u$ and $v$ components of velocity have a phase relationship, suggesting flow with a dominant direction. The $u$ and $v$ components of velocities were used to determine the dominant flow direction/angle using the relationship $\tan ^{-1}(v / u)$, and it should be noted that this flow direction is based on the instrument coordinate system, and does not show direction in ENU coordinate system. An histogram of the horizontal direction is shown in Figure 3.5(a). As shown here, the dominant flow directions of the horizontal velocities change depending on the tidal cycle. In order to gain a better understanding of the horizontal flow directions, the polar plot of the horizontal velocity vectors was prepared, and is shown in Figure 3.5(b). Furthermore, the horizontal velocities had greater spread during flood (shown with red marker) as compared to the ebb (shown with blue marker), as shown in the figure.

A mean pressure fluctuation is shown in Figure 3.6. As shown here, the mean pressure also captures the tidal behavior at the site. To understand the relationship between the velocity and pressure, the mean $u$ component of velocity and mean pressure data for days $5 / 12-5 / 18$, are shown Figure 3.7. The velocity and pressure show a high correlation, with velocity lagging behind the pressure variation by around half an hour.

\subsubsection{ADCP}

ADCP measurements were performed at the Marrowstone Island site for two weeks. The ADCP acquired velocity profile data from a depth of $2.6 \mathrm{~m}$ above the seabed to the surface, with a resolution of $0.5 \mathrm{~m}$. After quality control of ADCP data, and accurate determination of the 
Echo intensity - beam-1, (count)

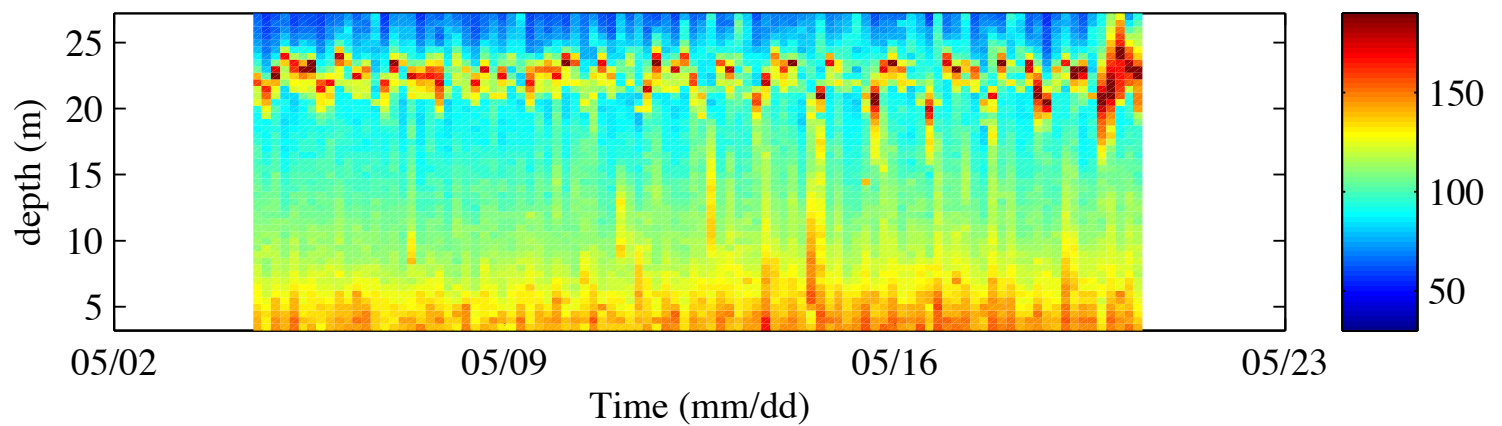

Echo intensity - beam-2, (count)

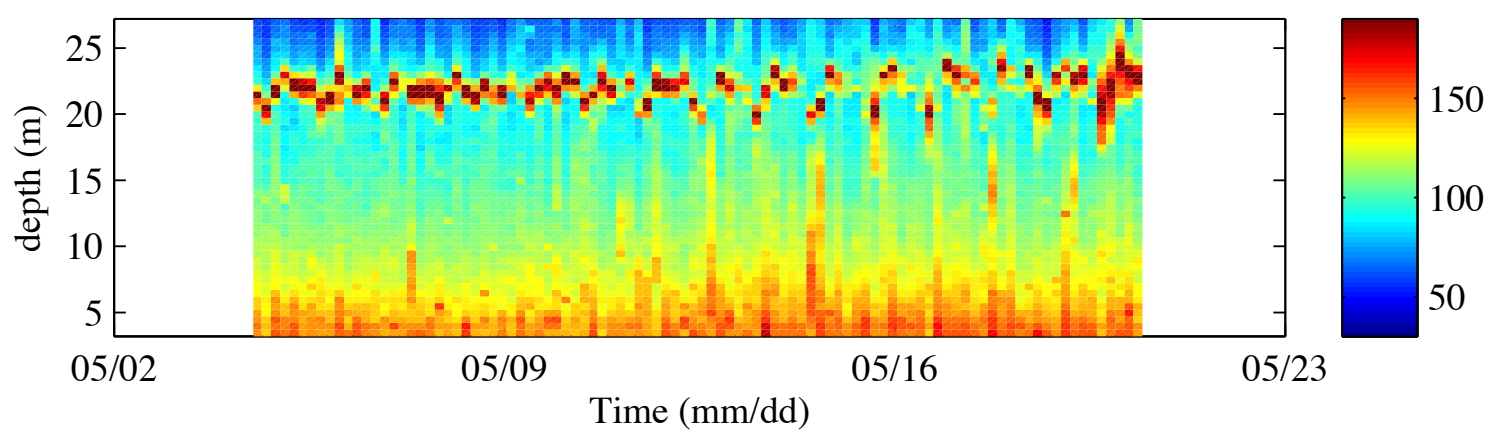

Echo intensity - beam-3, (count)

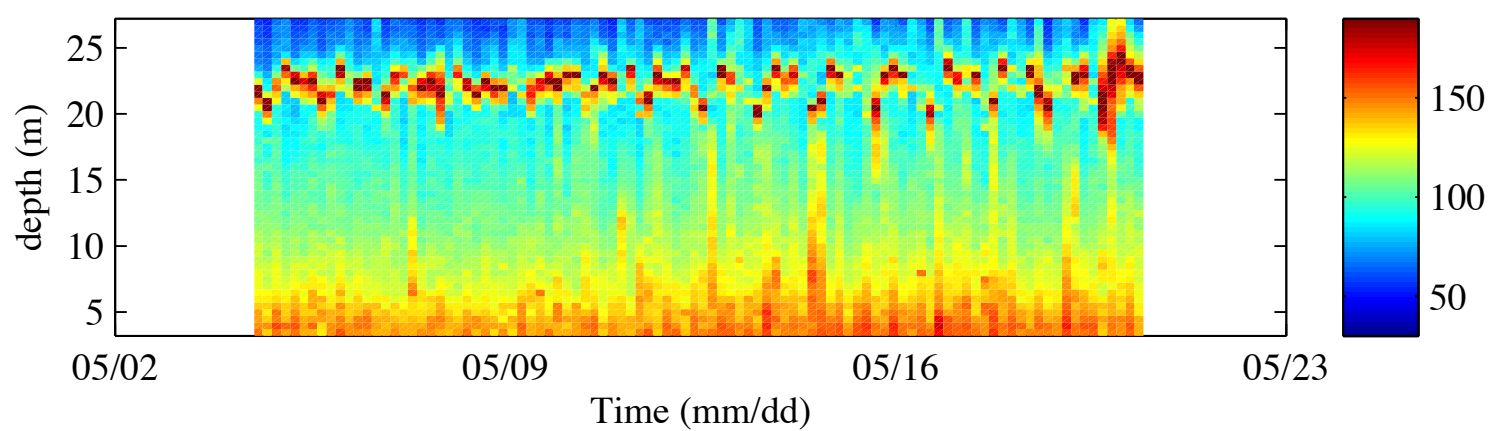

Echo intensity - beam-4, (count)

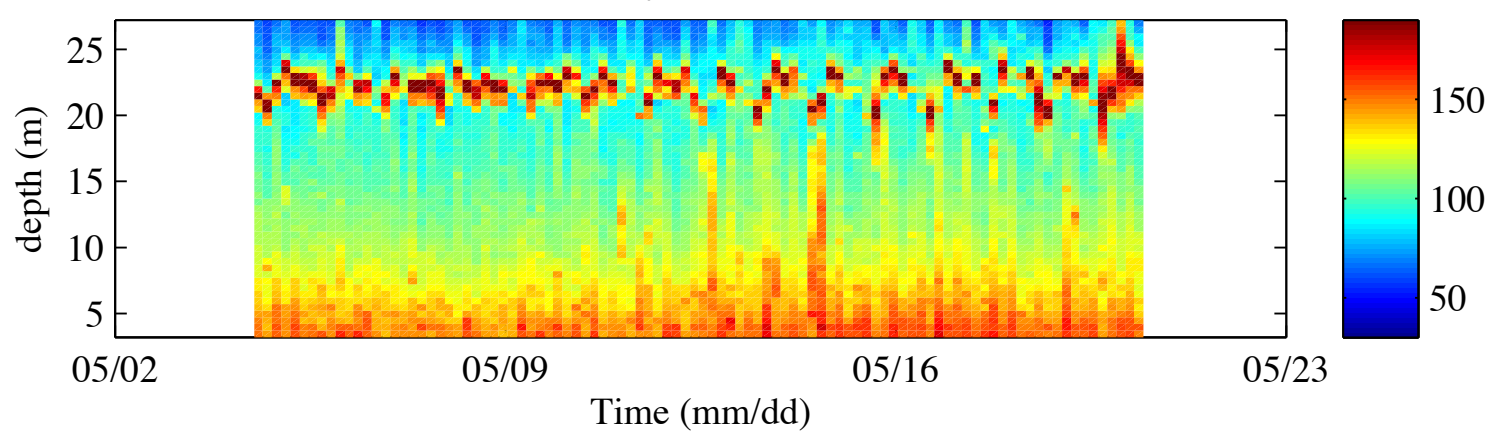

Figure 3.2. Echo intensity for each acoustic beam from ADCP. 


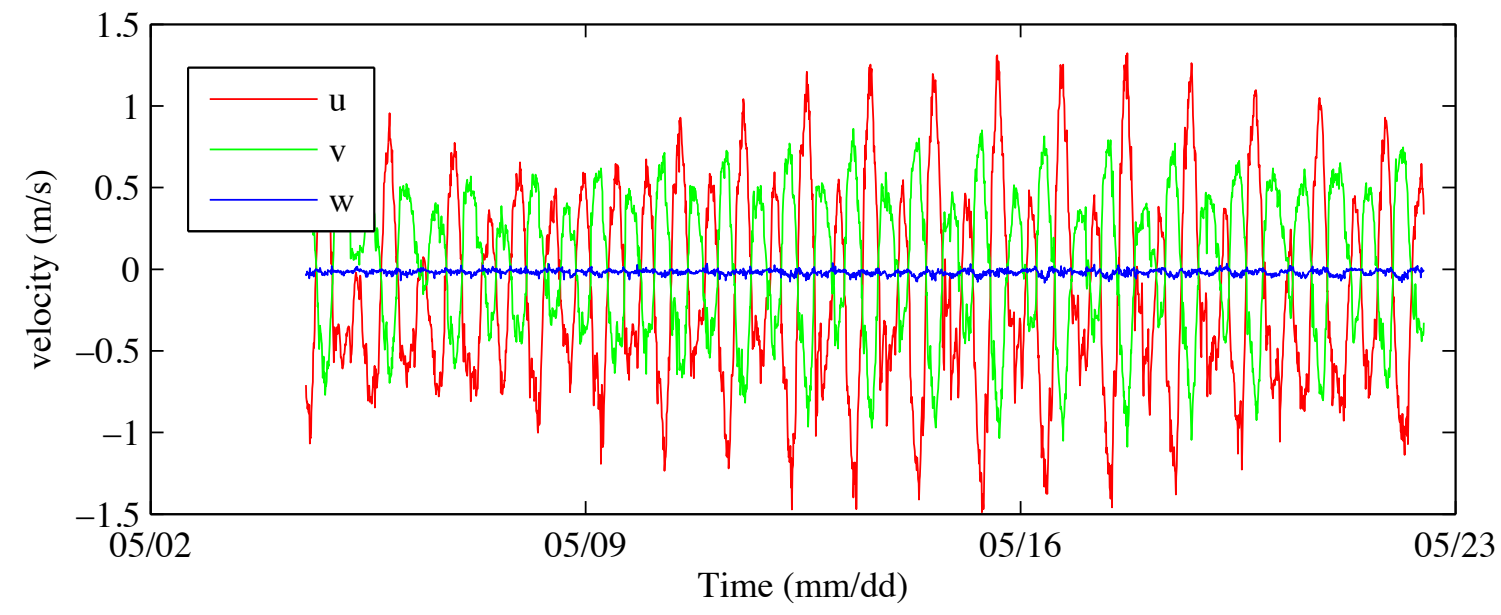

Figure 3.3. Mean velocities (instrument coordinate system) for each burst during ADV deployment at Marrowstone Island site.

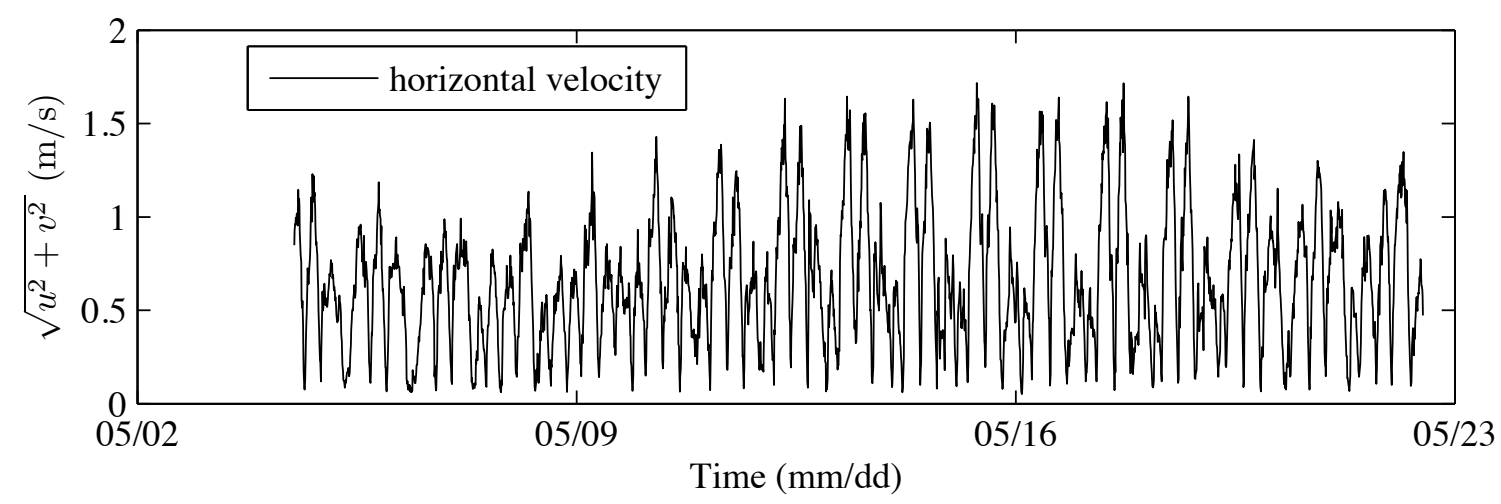

Figure 3.4. Magnitude of mean horizontal velocities (instrument coordinate system) for each burst during ADV deployment at Marrowstone Island site.

air-water interface, beam velocity data was plotted, and is shown in Figure 3.8. In the figure, the solid black line represents the water column height during each measurement. Using these quality controlled beam velocities, the horizontal velocity magnitude was determined. The horizontal velocity magnitude along with the direction is shown in Figure 3.9. As shown here, the horizontal velocities have a dominant flow direction depending on the tidal cycle. The horizontal velocity magnitudes and directions at three different heights were extracted: (1) $4.6 \mathrm{~m}$ (i. e. at base of MHK devices), (2) $10.0 \mathrm{~m}$ (i. e. at hub of MHK devices), and (3) $15.0 \mathrm{~m}$ (i. e. at top of MHK devices). These velocity direction histograms and velocity vectors are shown in Figure 3.11 and 3.12. As observed from these figures, there is a slight asymmetry in the flow direction as height from the seabed increases, which may be due to a bathymetric feature of the Marrowstone Island site. Furthermore, there is a decrease in the spread of the angular variation, suggesting that the flow had lesser variation closer to the surface.

To understand better the velocity profile at the Marrowstone Island site, the horizontal velocity magnitude at $4.6 \mathrm{~m}$ above seabed, along with $u, v$ and $w$ velocity profiles are shown in the Figure 


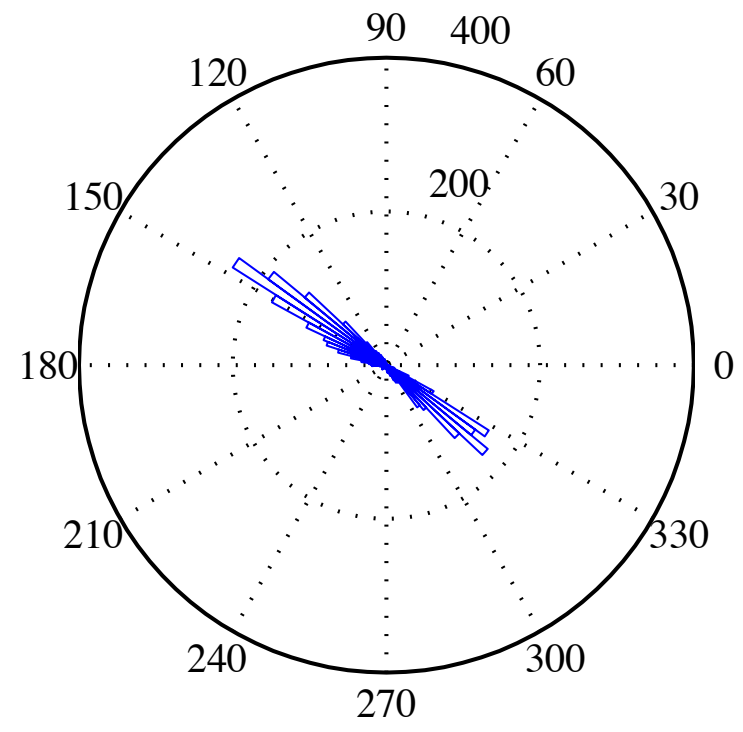

Degree

(a) Direction histogram

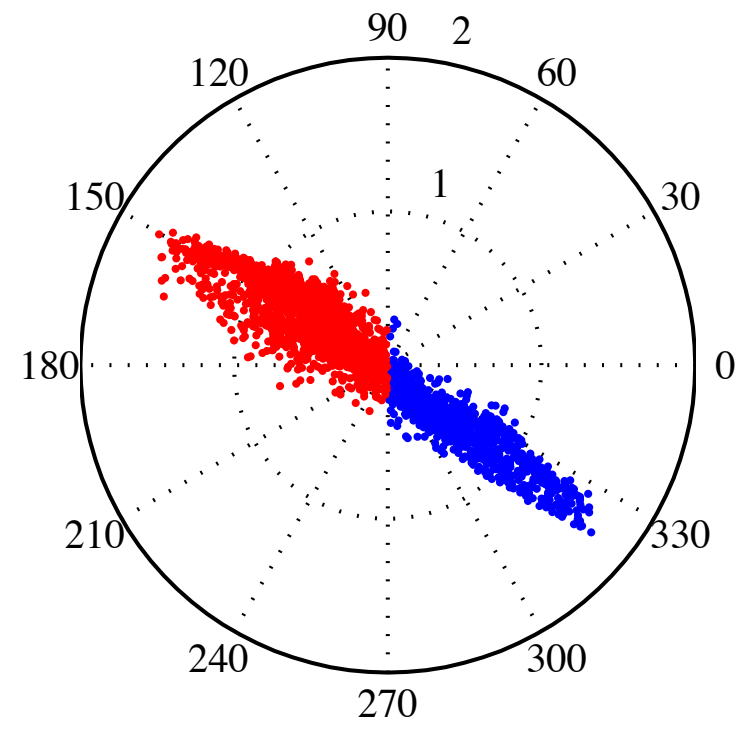

Horizontal velocity $(\mathrm{m} / \mathrm{s})$

(b) horizontal velocity

Figure 3.5. (a) Histogram of the horizontal velocity direction(instrument coordinate system), and (b) horizontal velocity vector with magnitude and direction (instrument coordinate system).

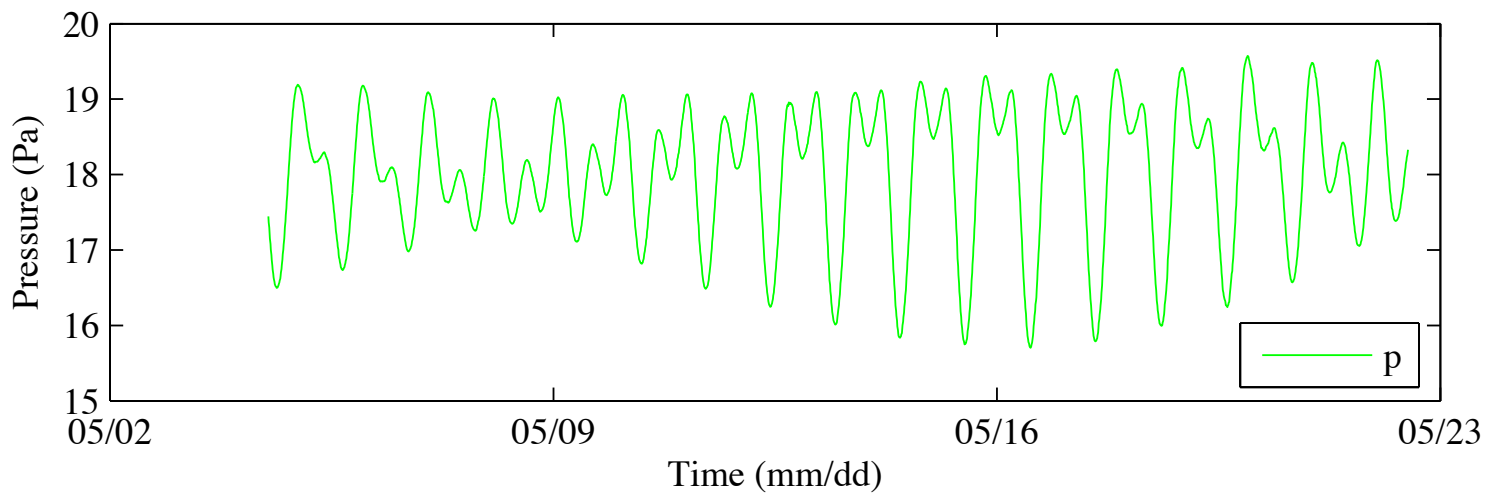

Figure 3.6. Mean pressure for each burst during ADV deployment at Marrowstone Island site.

3.10. The ensemble averaged $(u, v$ and $w)$ velocity profile is extracted for four different horizontal velocity magnitudes: 1) $0-0.4 \mathrm{~m} / \mathrm{s}, 2) 0.4-0.8 \mathrm{~m} / \mathrm{s}, 3) 0.8-1.2 \mathrm{~m} / \mathrm{s}$, and 4) $1.2-1.6 \mathrm{~m} / \mathrm{s}$. As shown in the figure, the ensemble averaged velocity profiles changed for different ranges of horizontal velocity magnitudes. For the horizontal velocity magnitudes less than $0.8 \mathrm{~m} / \mathrm{s}$, the $u$ component of velocity showed an almost linear profile, as seen in Figure 3.10. However, for velocity magnitudes higher than $0.8 \mathrm{~m} / \mathrm{s}$, the $u$ velocity profile followed the power law distribution, as shown in Figure 3.10. For the power law fit, ADCP velocity at $10 \mathrm{~m}$ is used as the reference velocity and the exponent for the power law is approximately $1 / 4$, as suggested by $\mathrm{Li}$ 


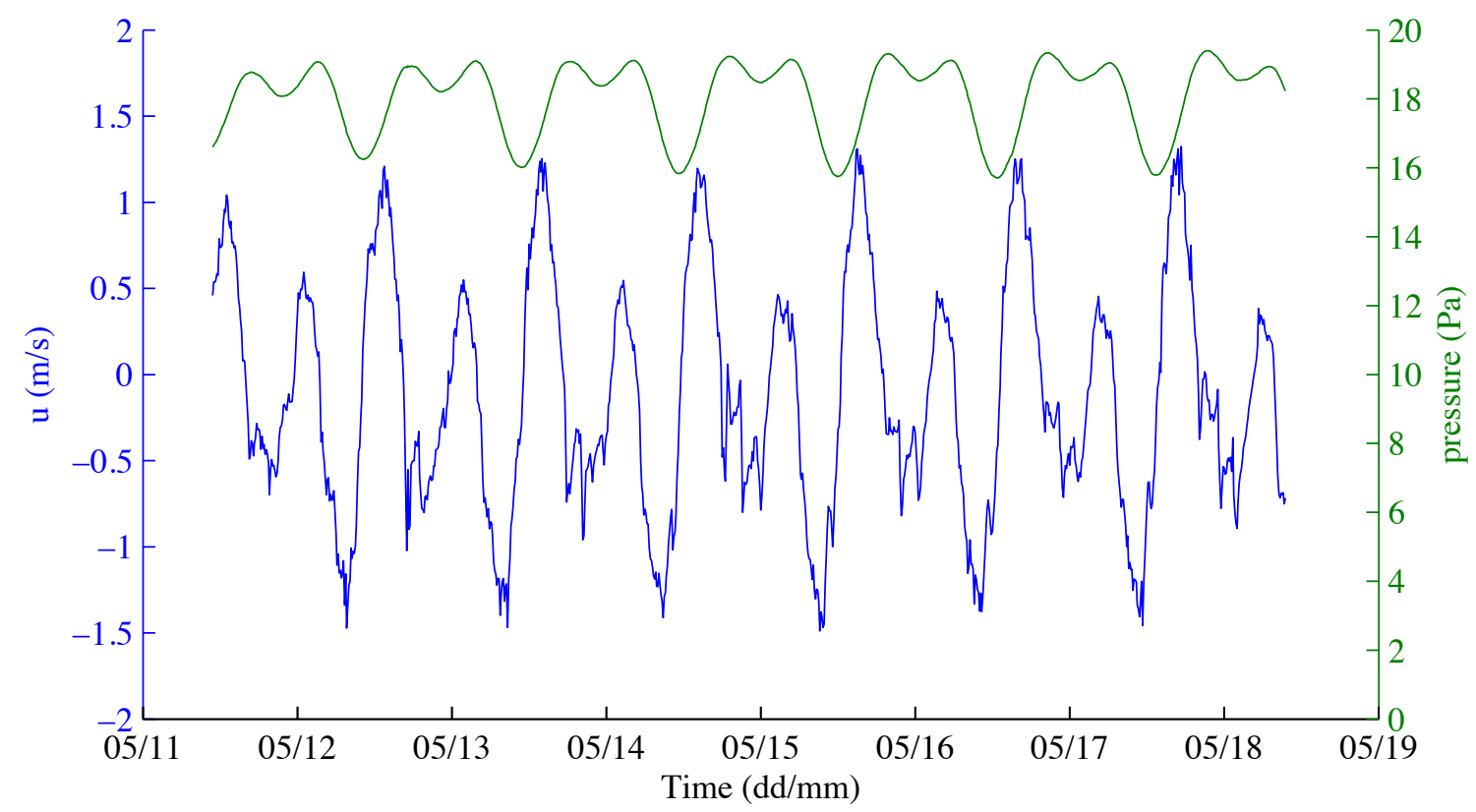

Figure 3.7. Mean pressure and mean $u$ component of velocity from ADV measurements for 12th May 2010 to 18th May 2010.

et al. (2010) in their study.

\subsection{CTD}

The CTD data shown in Figures 3.13(a)-(c), have a typical estuarine exchange flow. The temperature plot shows an increasing trend in mean temperature; this is because the measurements were performed during the month of May and as the peak summer period approaches, the mean temperature of the water bodies tends to increase. The salinity also shows an increasing trend which may be due to currents coming in from the Pacific Ocean, which increase the salinity, in spite of a corresponding increase in fresh water discharge during the late spring / early summer months. The depth measurements shown in this figure also show a tidal variation.

\subsection{Turbulence quantities}

To understand the nature of turbulence in the tidal flow at the Marrowstone Island site, basic turbulent quantities like mean, standard deviation and turbulent intensity were calculated. Figure 3.14, shows the means, standard deviations and turbulent intensities for u-component of velocity from each ADV burst for entire deployment. Mean flow shows the tidal variation, and the standard deviation follows the tidal fluctuation, suggesting that the mean flow quantity is the source of the turbulence generated. Turbulent intensity $(T I)$ is defined as the ratio of fluctuation(i.e. the standard deviation) to the mean quantity, which is given as

$$
T I(\%)=\frac{\sigma_{u, c} * 100}{\langle u\rangle},
$$



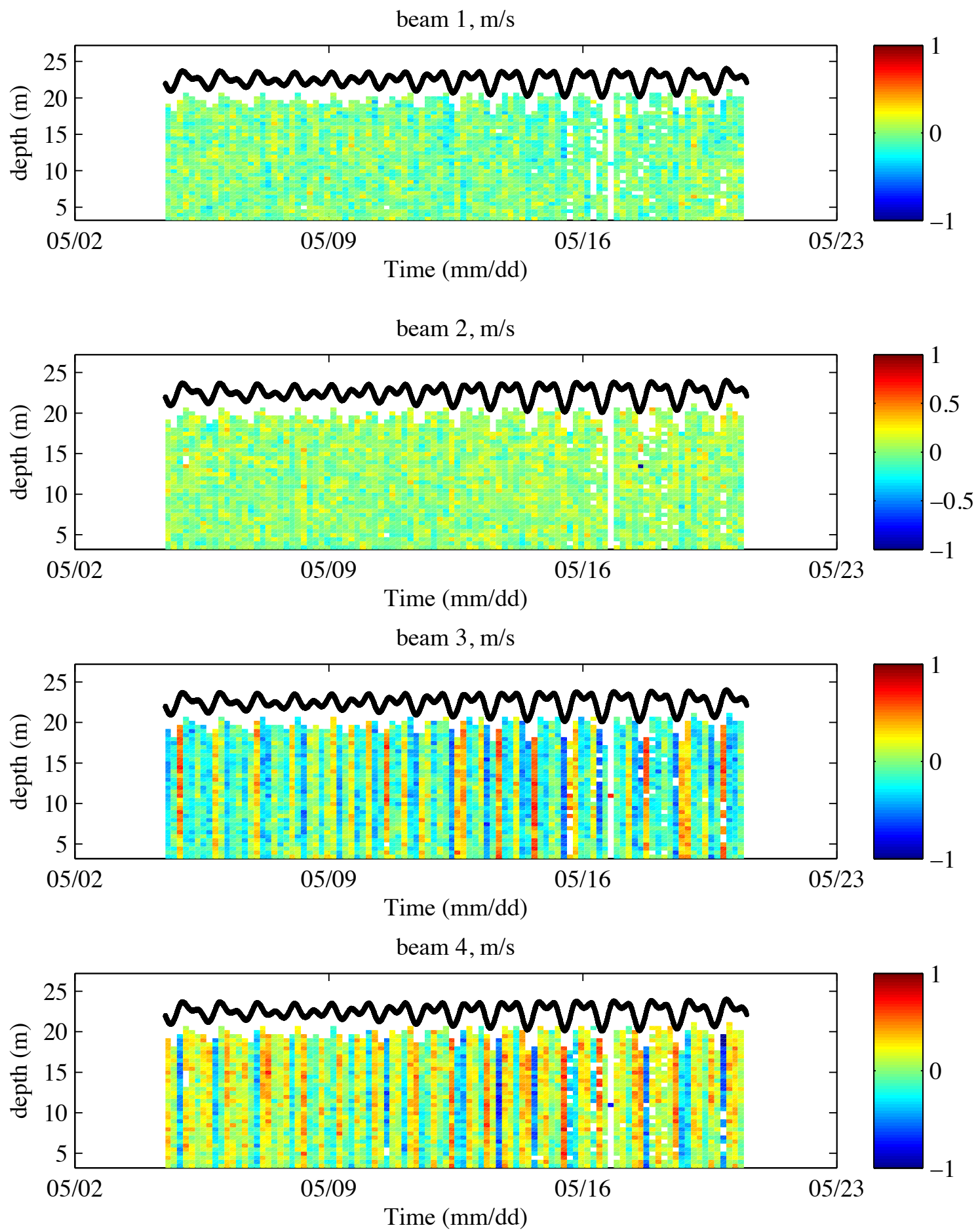

Figure 3.8. Velocities along the beam after quality control for ADCP measurements performed at Marrowstone Island site, where solid black line represents the water depth. 

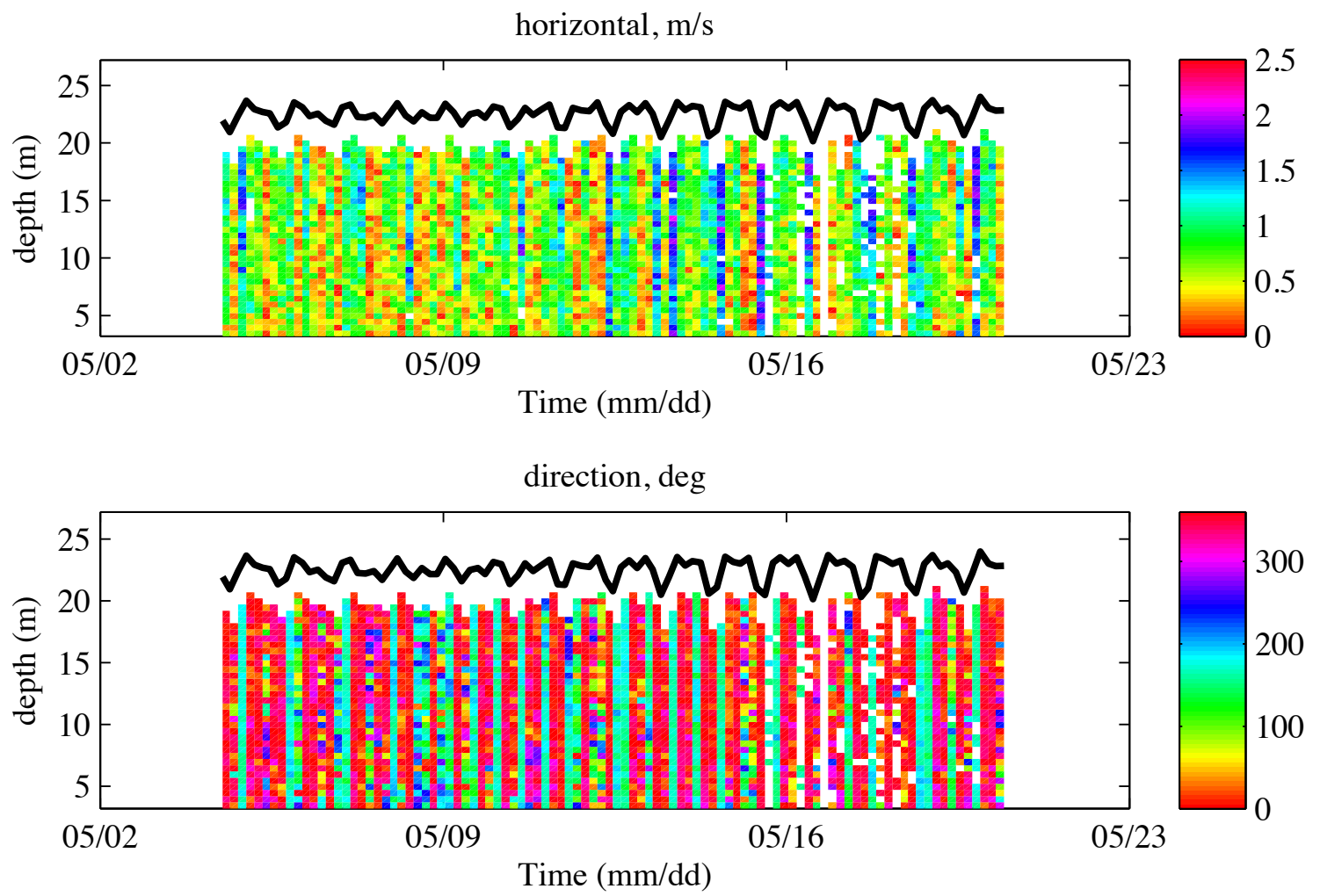

Figure 3.9. Horizontal velocities magnitude along with flow direction for ADCP measurement performed at Marrowstone Island site, where solid black line represents the water depth.

where $\sigma_{u, c}$ is the corrected standard deviation, and $\langle u\rangle$ is the mean velocity of each burst. Turbulent intensity for the ADV measurements for the entire survey are shown in the bottom panel of Figure 3.14. As shown in the figure, there is a significant fluctuation from one burst to another. Furthermore, it should also be noted that for some bursts, the turbulent intensity had significantly higher values, this is due a a very low mean velocity. The red marker shows the turbulent intensities for the non-slack period. The non-slack condition for this site is defined as the time when the horizontal velocity magnitude is greater than $0.8 \mathrm{~m} / \mathrm{s}$.

Since the horizontal velocity components had significantly higher energy as compared to the vertical velocity component, the standard deviation and turbulent intensities of horizontal velocities were calculated, as shown in Table 3.1. The table shows the mean and maximum values of standard deviation and turbulent intensity from ADCP and ADV measurements. The standard deviation of the horizontal velocity calculated from ADCP measurements was significantly higher than the standard deviation calculated from ADV measurements. This is due to significantly higher noise in the ADCP measurements as compared to ADV measurements. Therefore the correction in the standard deviation was performed using Equation 3.2. After performing the correction, the standard deviation from ADCP and ADV showed similar values. Using these corrected standard deviation values, the corrected turbulent intensities were calculated for both the ADCP and ADV measurements. The corrected mean turbulent intensity in horizon- 

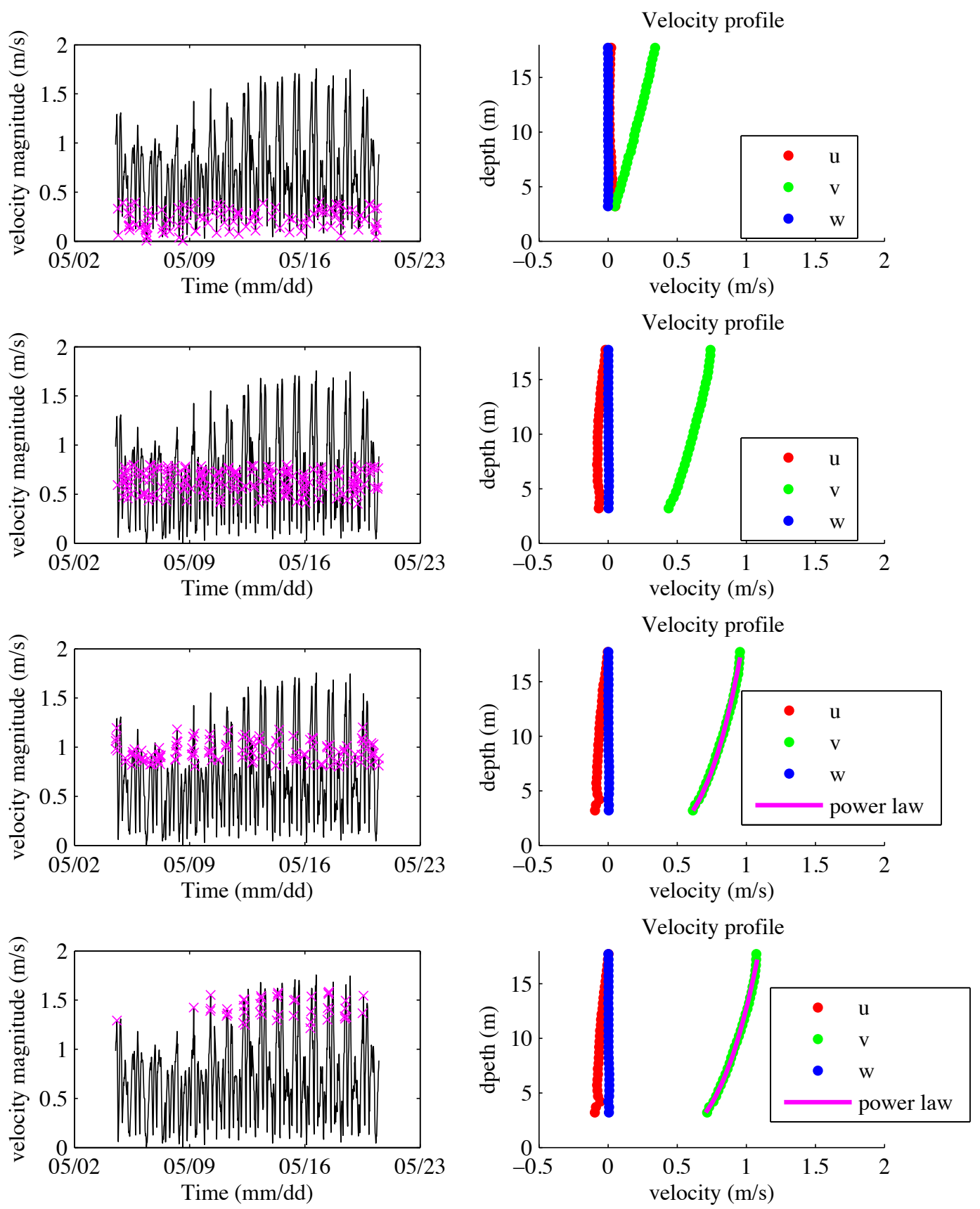

Figure 3.10. Velocity profiles for four different velocity magnitude ranges from ADCP measurements. The range of horizontal velocity magnitude from top to bottom: (1) $0-0.4 \mathrm{~m} / \mathrm{s}$, (2) $0.4-0.8 \mathrm{~m} / \mathrm{s}$, (3) $0.8-1.2 \mathrm{~m} / \mathrm{s}$, and (4) $1.2-1.6 \mathrm{~m} / \mathrm{s}$. Cross marks represent data points used for ensemble averaging. The exponent for the power law fit is approximately $1 / 4$. 


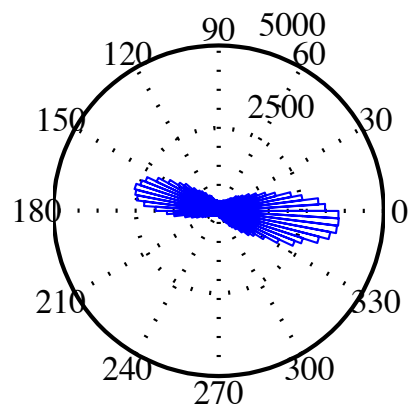

(a)

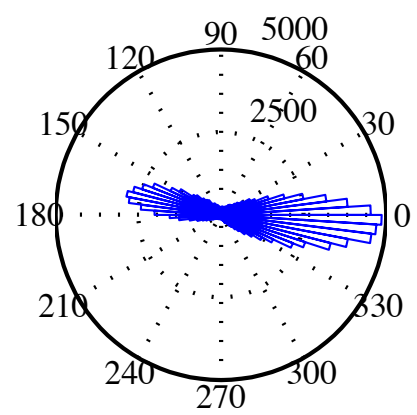

(b)

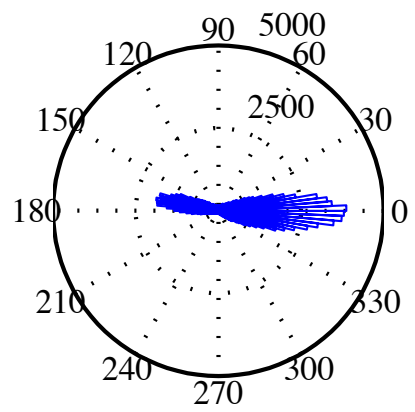

(c)

Figure 3.11. Histogram of the horizontal velocity direction (ENU coordinates system) for different heights from ADCP measurements: (a) $4.71 \mathrm{~m}$ from seabed, (b) $10.21 \mathrm{~m}$ from seabed, and (c) $15.21 \mathrm{~m}$ from seabed.

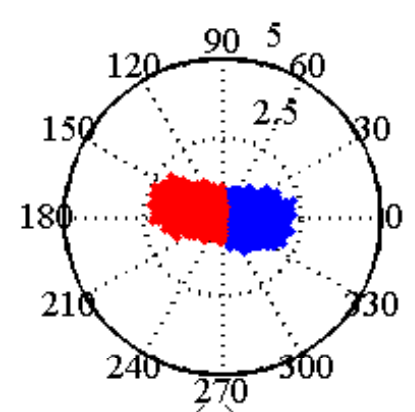

(a)

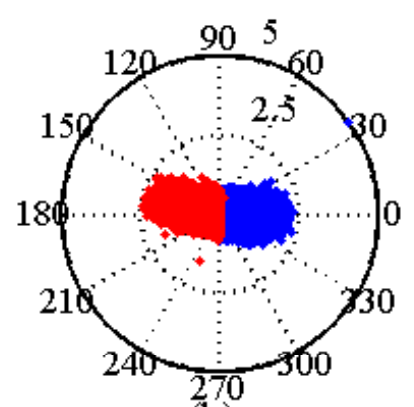

(b)

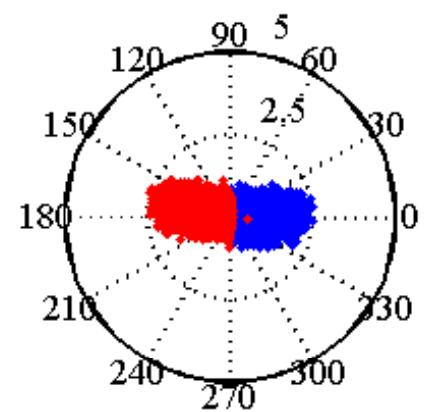

(c)

Figure 3.12. Polar plot of the horizontal velocity (magnitude along with direction(ENU coordinates system)) for different heights from ADCP measurements: (a) $4.71 \mathrm{~m}$ from seabed, (b) $10.21 \mathrm{~m}$ from seabed, and (c) $15.21 \mathrm{~m}$ from seabed.

tal velocity was around $10 \%$. Thus, after performing the corrections, both ADV and ADCP measurements showed similar standard deviations and turbulent intensities.

The next parameter to be determined in turbulence quantification is turbulent kinetic energy (TKE), which is defined as

$$
T K E=\frac{1}{2}\left(\sigma_{u, c}^{2}+\sigma_{v, c}^{2}+\sigma_{w, c}^{2}\right),
$$

where $\sigma_{u, c}, \sigma_{v, c}$, and $\sigma_{w, c}$ are corrected velocity fluctuations using Equation 3.2. Figure 3.15, shows the mean TKE for the entire deployment. As shown in the figure, TKE also follows the tidal variation. Therefore, for the MHK devices, tidal variation may be an important design criterion. A similar behavior in response to to turbulent fluctuations is also seen in wind turbines, where turbulent fluctuations reduce turbine performance and cause material fatigue, which in turn decrease the lifespan of the devices. 

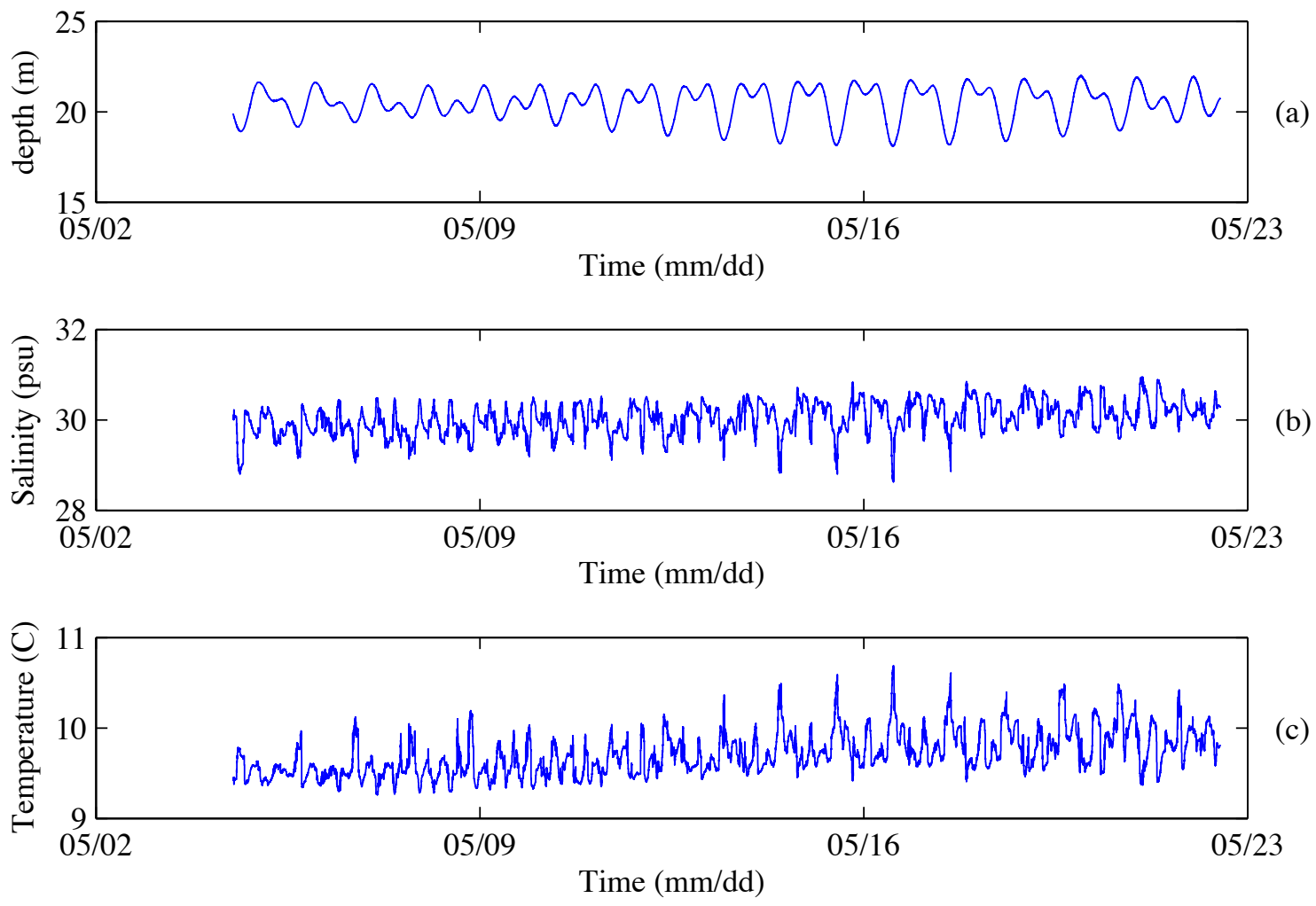

Figure 3.13. CTD measurements at Marrowstone Island site: (a) water depth for entire deployment, (b) salinity of the site for entire deployment, and (c) mean temperature of the site for entire deployment.

Table 3.1. Summary of horizontal velocity statistic from ADV and ADCP with and without correction for Doppler noise.

\begin{tabular}{|c|c|c|}
\hline & ADV & ADCP \\
\hline $\mathrm{n}$ & 0.040 & 0.195 \\
\hline Average values & & \\
\hline$\sigma_{\text {hvel }}(\mathrm{m} / \mathrm{s})$ & 0.09 & 0.22 \\
$\sigma_{\text {hvel }, c}(\mathrm{~m} / \mathrm{s})$ & 0.08 & 0.11 \\
$T I_{\text {hvel }}(\%)$ & 8.0 & 21.0 \\
$T I_{\text {hvel }, c}(\%)$ & 7.0 & 10.0 \\
\hline Maximum values & & \\
\hline$\sigma_{\text {hvel }}(\mathrm{m} / \mathrm{s})$ & 0.22 & 0.31 \\
$\sigma_{\text {hvel }, c}(\mathrm{~m} / \mathrm{s})$ & 0.21 & 0.24 \\
& & \\
$T I_{\text {hvel }}(\%)$ & 15.0 & 30.0 \\
$T I_{\text {hvel }, c}(\%)$ & 14.0 & 18.0 \\
\hline
\end{tabular}



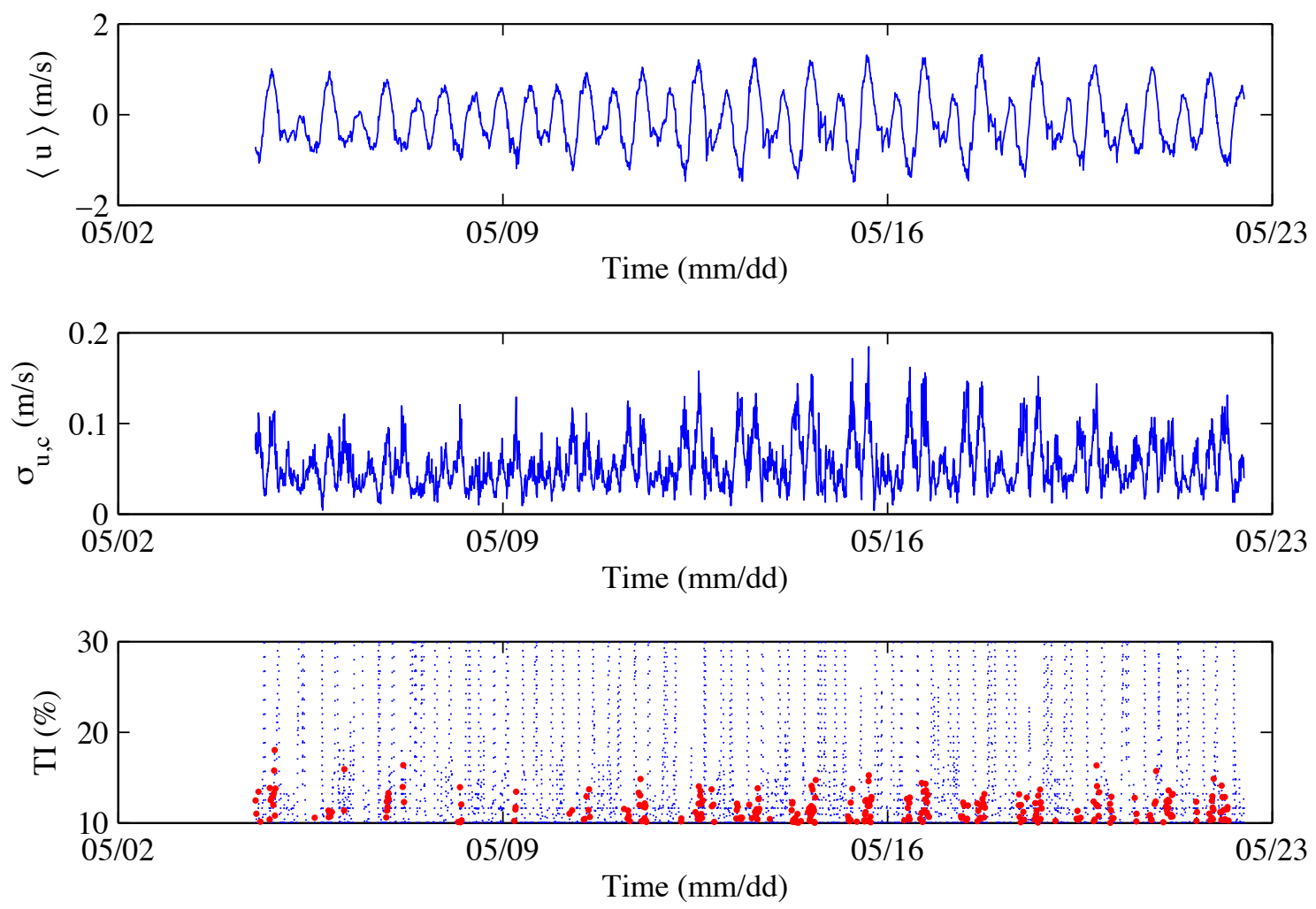

Figure 3.14. Top plot showing mean $u$ component of velocity, middle plot showing corrected standard deviation, and bottom plot showing turbulent intensities from ADV measurements.

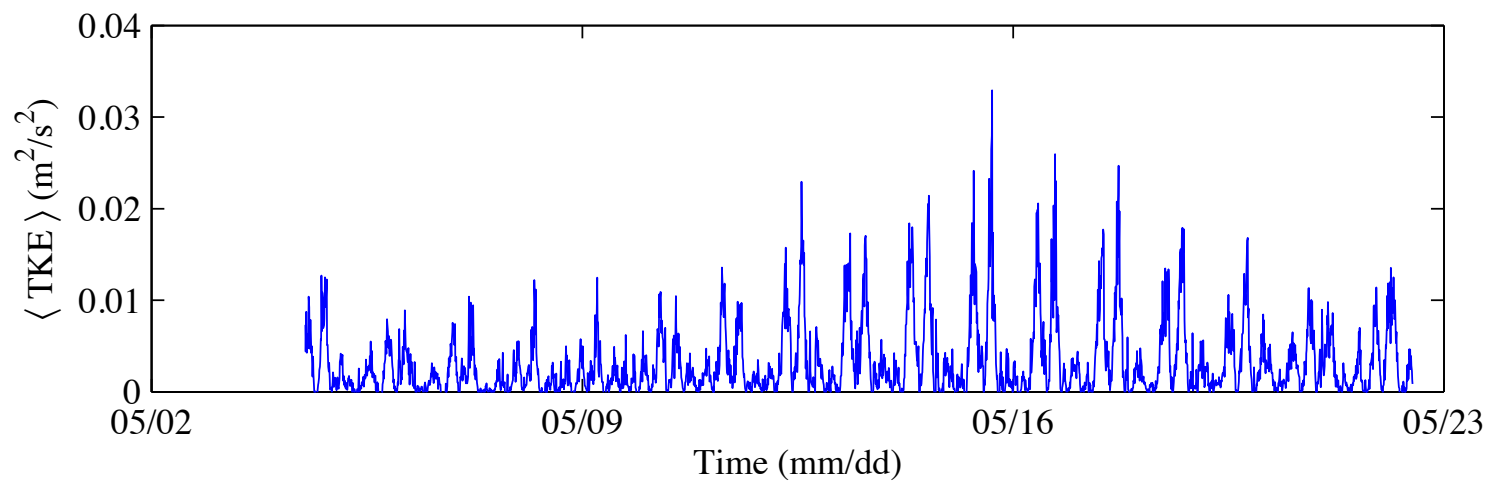

Figure 3.15. Average TKE for each burst for entire ADV deployment. 


\subsection{Spectrum}

To understand in detail about the flow characteristics, the power spectrum/ auto-spectral densities were calculated from ADV measurements for each velocity component. For each ADV burst, the velocities were assumed to be stationary. Therefore, for each individual burst, auto-spectral densities could be determined. Furthermore, as shown in previous results, the fluctuating quantities/ turbulence for this study are dependent on the mean velocities. Therefore, an ensemble average of the power spectrum can be calculated for the flow conditions with same mean values. Figure 3.16(a) shows the horizontal velocity magnitude from the ADV measurements for the entire deployment. In this figure, the non-slack velocity periods are marked by blue dots. For this study, the non-slack condition is defined as the time when the mean horizontal velocity had magnitude greater than $0.8 \mathrm{~m} / \mathrm{s}$, and the slack condition is defined as the time when the horizontal velocity had magnitude less than $0.8 \mathrm{~m} / \mathrm{s}$. Figures 3.16(b) and (c) show typical nonslack and slack power spectra for all components of velocity respectively. As observed from the figure, the power spectrum is noisy, which is due to the presence of high-frequency noise in the ADV measurements. Figures 3.16(d) and (e) shows the averaged power spectrum for all components of velocity for non-slack and slack conditions respectively. These figures shows typical turbulent flow behavior i. e. for the inertial sub-range portion of the spectra has a slope of $-5 / 3$. It is also observed in these power spectrum plots that at higher frequencies, the spectrum tends to become horizontal. This is due to the presence of noise in the ADV measurements. Moreover, the horizontal components of velocity show a higher noise level as compared to the vertical component $(w)$ of velocity, as observed in the figure. This difference in noise levels for different components of velocity is characteristic of ADV measurements. Data acquired from ADCP measurements near the ADV measurements location were also used to calculate the power spectrum and they were compared with the spectrum acquired from ADV measurements. Figure 3.17 shows the spectra from both ADCP and ADV measurements. As observed from the figure, the ADCP measurements do not follow the spectrum plot from the ADV measurements. This is due to a significantly higher level of noise in ADCP measurements as compared to ADV measurements. Here, it is also noted that the spectrum for $w$ component of velocity has relatively lower level of noise as compared to $u$ and $v$ components of velocity. It is difficult to extract turbulence information from the ADCP measurements because of low sampling frequency and presence of higher noise level in the measurements. However, ADCP data was used to calculate the power spectrum at three different heights from the seabed i. e. $4.21 \mathrm{~m}$ (close to base height of MHK device), $10.21 \mathrm{~m}$ (close to hub height of MHK device) and $15.21 \mathrm{~m}$ (close to top of MHK device). The spectra from ADCP measurements at these heights are shown in Figure 3.18; no significant change in spectra trend is observed. This is due to the significantly higher level of noise in and large sampling volume of ADCP measurements.

\subsection{Length and Time scales}

The Lagrangian integral length $\left(\mathrm{L}_{\mathrm{L}}\right)$ and time $\left(\mathrm{T}_{\mathrm{L}}\right)$ scales represent the length and time for which the turbulent flow is strongly coherent or correlated. These parameters are essential for characterizing the production and dissipation of energy in turbulent flows and are also used in numerical studies focussing on turbulent flow modeling and simulations. In some turbulence experiments, these scales can be accurately estimated from the flow features. For instance, the turbulent flow 
inside a tube can have the largest length scale of the order of pipe diameter, while the time scale can be calculated by dividing the length scale by the mean flow. These scales are not obvious in some turbulent flows, they can however be calculated using two-point correlation of the measured velocity field, and are defined by

$$
\begin{aligned}
\mathrm{T}_{\mathrm{L}} & =\int_{0}^{\infty} \rho(\tau), d \tau \\
\mathrm{L}_{\mathrm{L}} & =\bar{u} T_{L},
\end{aligned}
$$

where $\tau$ is the time lag, $\bar{u}$ is characteristic fluid flow velocity or the advection velocity of the eddies, and $\rho(\tau)$ is the auto-correlation function in the temporal domain. It should be noted that frozen turbulence hypothesis is used to estimate $L_{L}$ ( see equation 3.6). The velocity fields measured from ADV were used to calculate the auto-correlation functions for all components of velocities (i. e. $u, v$ and $w$ ) during non-slack and slack periods in the tidal cycle, and are shown in figures 3.19(a) and (b) respectively. As observed from these figures, the auto-correlation functions for the $u$ and $v$ components of velocities do not approach unity for time lag $(\tau)$ of zero. This is due to the presence of higher noise levels in the measurement of $u$ and $v$ components of velocities as compared to the vertical component $(w)$ of velocity. The higher noise levels increase the variance in the $u$ and $v$ components. Therefore, when the auto-correlation is normalized with these variances, it reaches a value lower than unity at zero time lag. The effect of higher noise levels in the auto-correlation functions is more pronounced during the slack period, as observed in figure 3.19 (b). In spite of the error produced by the noise in the auto-correlation functions, the relationship provided in equation 3.5 was used for calculating the time scales for slack and non-slack periods, which are given in table 3.2. As given in the equation, the limits of the integration are from zero to infinity. However, integration over infinity cannot be practically carried out in experiments, so it is performed over the limits zero to first zero-crossing of autocorrelation function. The length scales for slack and non-slack periods were calculated using equation 3.6, and are given in table 3.2.

Another important length scale in turbulence measurements is the Kolmogorov scale $\left(L_{k}\right)$, which defines the length scale of the smallest eddies and is given as

$$
\mathrm{L}_{\mathrm{k}}=\left(\frac{\mathrm{v}^{3}}{\varepsilon}\right)^{1 / 4}
$$

where $v$ is kinematic viscosity, and $\varepsilon$ is the dissipation rate. The Kolmogorov scale is of importance in numerical studies because it provides information about the smallest scale eddies present in the studied flow and therefore can be used to create the smallest grid in numerical studies for accurate turbulent flow simulations. For this study, the typical value of $v$ is $13.69 \times 10^{-7} \mathrm{~m}^{2} / \mathrm{s}$ and the estimated mean $\varepsilon$ value is $2.91 \times 10^{-4} \mathrm{~m}^{2} / \mathrm{s}^{3}$. Using these values of $k$ and $\varepsilon$, the Kolmogorov length scale is calculated to be $3.06 \times 10^{-4} \mathrm{~m}$. In oceans, this scale is typically of the order of $6 \times 10^{-5} \mathrm{~m}$ in turbulent regions and $0.01 \mathrm{~m}$ in abyssal ocean. 


\begin{tabular}{|c|cc|cc|cc|}
\hline & $u$ & $v$ & & $w$ & \\
\hline Tide & $T_{L}(s)$ & $L_{L}(m)$ & $T_{L}(s)$ & $L_{L}(m)$ & $T_{L}(s)$ & $L_{L}(m)$ \\
\hline Non-Slack & 2.00 & 1.78 & 1.33 & 0.56 & 0.95 & 0.028 \\
\hline Slack & 1.22 & 0.43 & 0.87 & 0.38 & 1.42 & 0.022 \\
\hline
\end{tabular}

Table 3.2. Integral length and time scales

\subsection{Coherent TKE}

Coherent turbulence can be characterized by coherent turbulent kinetic energy $E_{c o h}$, which is defined as

$$
E_{c o h}=\frac{1}{2}\left\{\left[u^{\prime} w^{\prime}\right]^{2}+\left[u^{\prime} v^{\prime}\right]^{2}+\left[v^{\prime} w^{\prime}\right]^{2}\right\}^{\frac{1}{2}}
$$

where $u^{\prime}, v^{\prime}$, and $w^{\prime}$ are the velocity fluctuations in $x, y$ and $z$ directions respectively. The potential importance of coherent turbulence in the operation of MHK devices is illustrated in a study done by Kelley et al. (2005) on wind turbine blades. This study suggests that blade fatigue damages occur during night time from coherent turbulence in the atmospheric boundary layer. Figure 3.20(a) shows the $E_{c o h}$ for the ADV survey performed on 15 May 2010 at 08:30 hrs, when the TKE had a significantly higher value. From this figure, the impact of $E_{c o h}$ on the MHK devices is not obvious. Wavelet analysisKelley and Osgood (2000) was therefore used to understand the temporal-frequency behavior of $E_{c o h}$ and its impact on MHK devices. Following Kelley and Osgood, a continuous wavelet transform function, with a Morlet wavelet as the mother function, was used. The temporal-frequency spectrum analysis for $E_{c o h}$ is shown in Figure 3.20(b) (red represents the highest energy and blue represents lowest energy). As shown in the figure, $E_{c o h}$ has energy in both lower as well as higher frequencies; at higher frequencies, the structures are difficult to observe due to non-linear nature of the frequency scale. Figure 3.20(c) shows the wavelet transform at higher frequencies. As observed in the figure, these higher frequencies have energy in them, suggesting presence of "eddies" at these frequencies. Figure 3.21(a) shows the $E_{c o h}$ for the case when the TKE is at a minimum value. As shown in the figure, the $E_{c o h}$ is significantly lower than in the previously shown case. The Figures 3.21(b)(c) shows the wavelet analysis on this $E_{c o h}$. The temporal-frequency analysis shows "eddies" at low frequencies. However, at higher frequencies, (i. e. frequencies greater than $8 \mathrm{~Hz}$ ), the energy-containing structures are significantly less as compared to the higher TKE case described above. This wavelet analysis approach is similar to that used by Kelley et al. (2005). In their study, a 1:1 correspondence was observed between the spectral frequencies of coherent turbulence $\left(E_{c o h}\right)$ and vibratory response of the turbine blades. They described this phenomenon as "resonant coupling", and suggested it to be the reason for blade fatigue damage in wind turbines. MHK devices may show behavior similar to that of wind turbines; hence the approaches used to interpret the results obtained from experiments pertaining to wind turbines can be extrapolated to experiments performed on MHK devices as well, albeit with caution. Based on the temporalfrequency behavior of $E_{c o h}$ obtained in this study, MHK devices may be expected to exhibit similar response at higher frequencies due to the presence of energies at these frequencies in the $E_{c o h}$. However, further detailed study and thorough analysis needs to be performed in order to conclusively demonstrate and understand the structural response of MHK devices in various inflow conditions. 


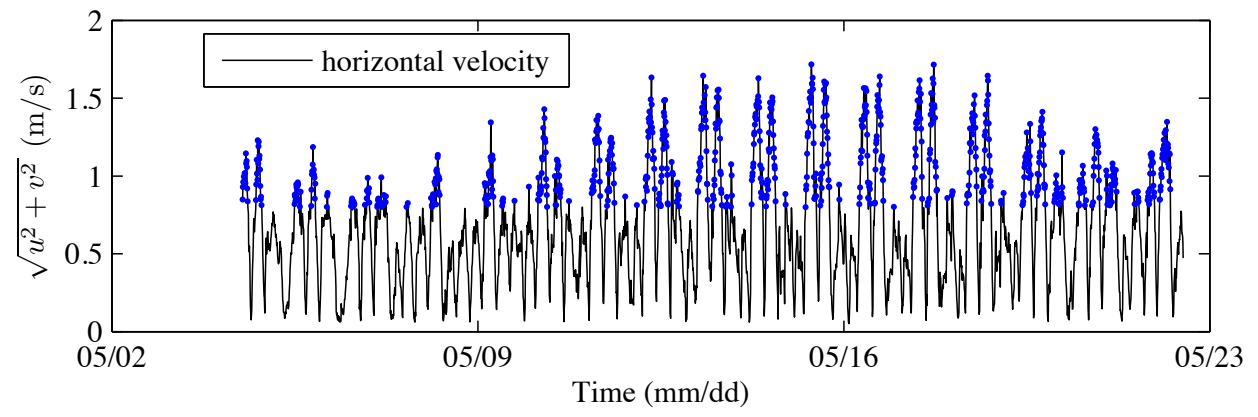

(a) non-slack velocity

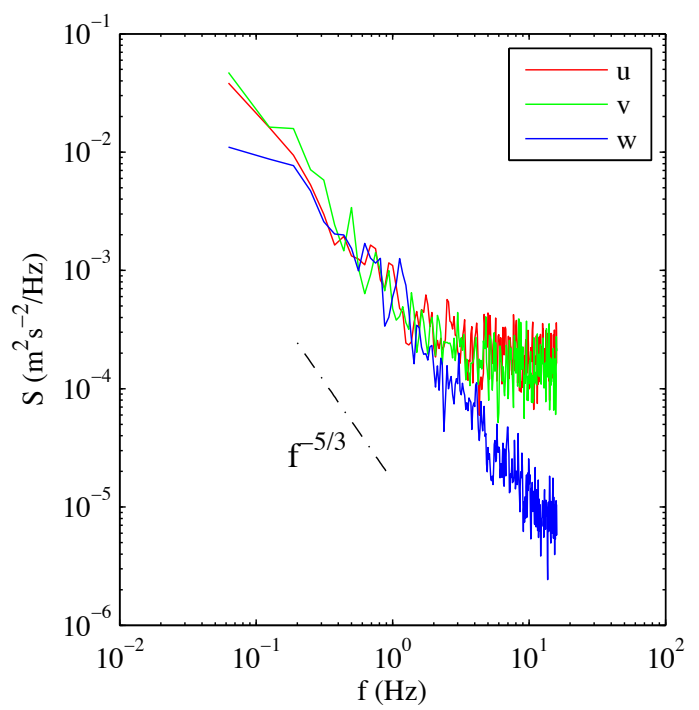

(b) non-slack spectra single ADV burst

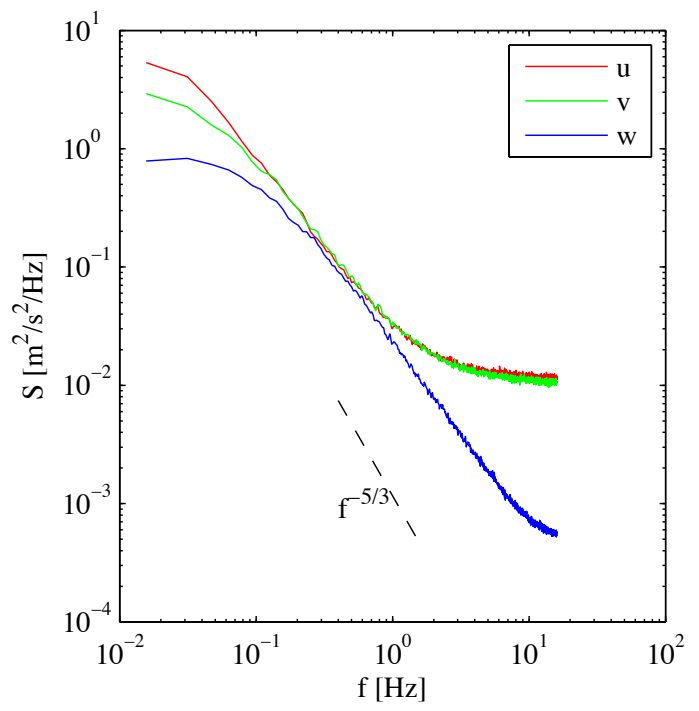

(d) non-slack spectra ensemble average

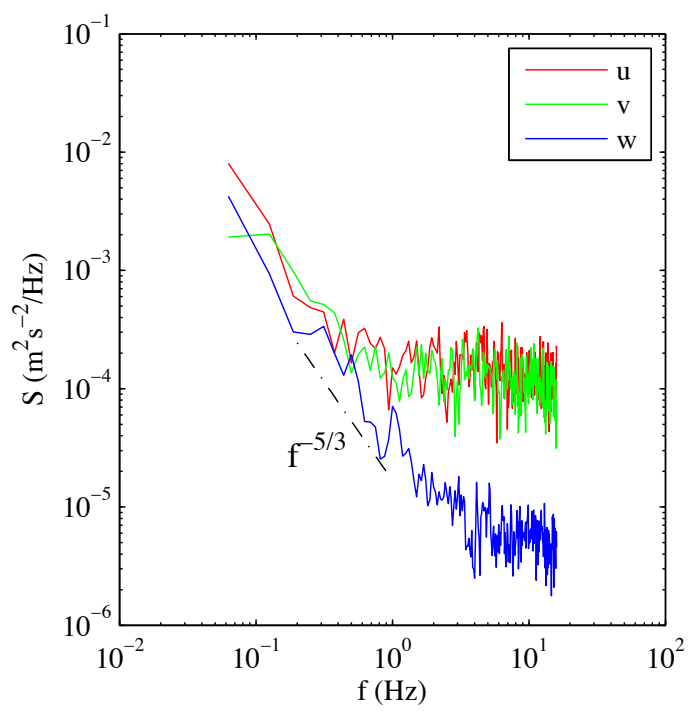

(c) slack spectra single ADV burst

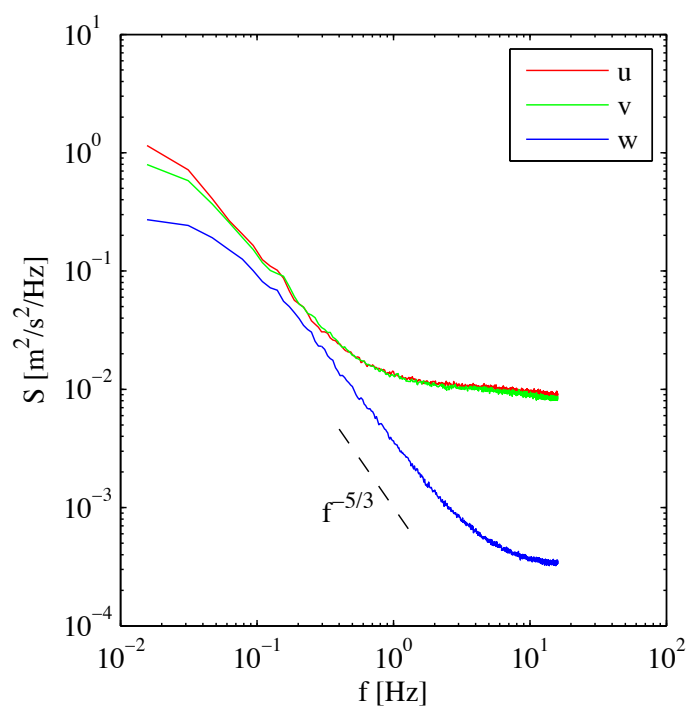

(e) slack spectra ensemble average

Figure 3.16. (a) Mean ADV velocity magnitude non-slack velocity shown with blue marker, (b) and (c) show the auto-spectra of velocity components for a single burst, for non-slack and slack condition respectively, (d) and (e) show the ensemble average of auto-spectra of velocity components, for non-slack and slack condition respectively. The commonly observed $f^{-5 / 3}$ shape is shown by the dashed line. 


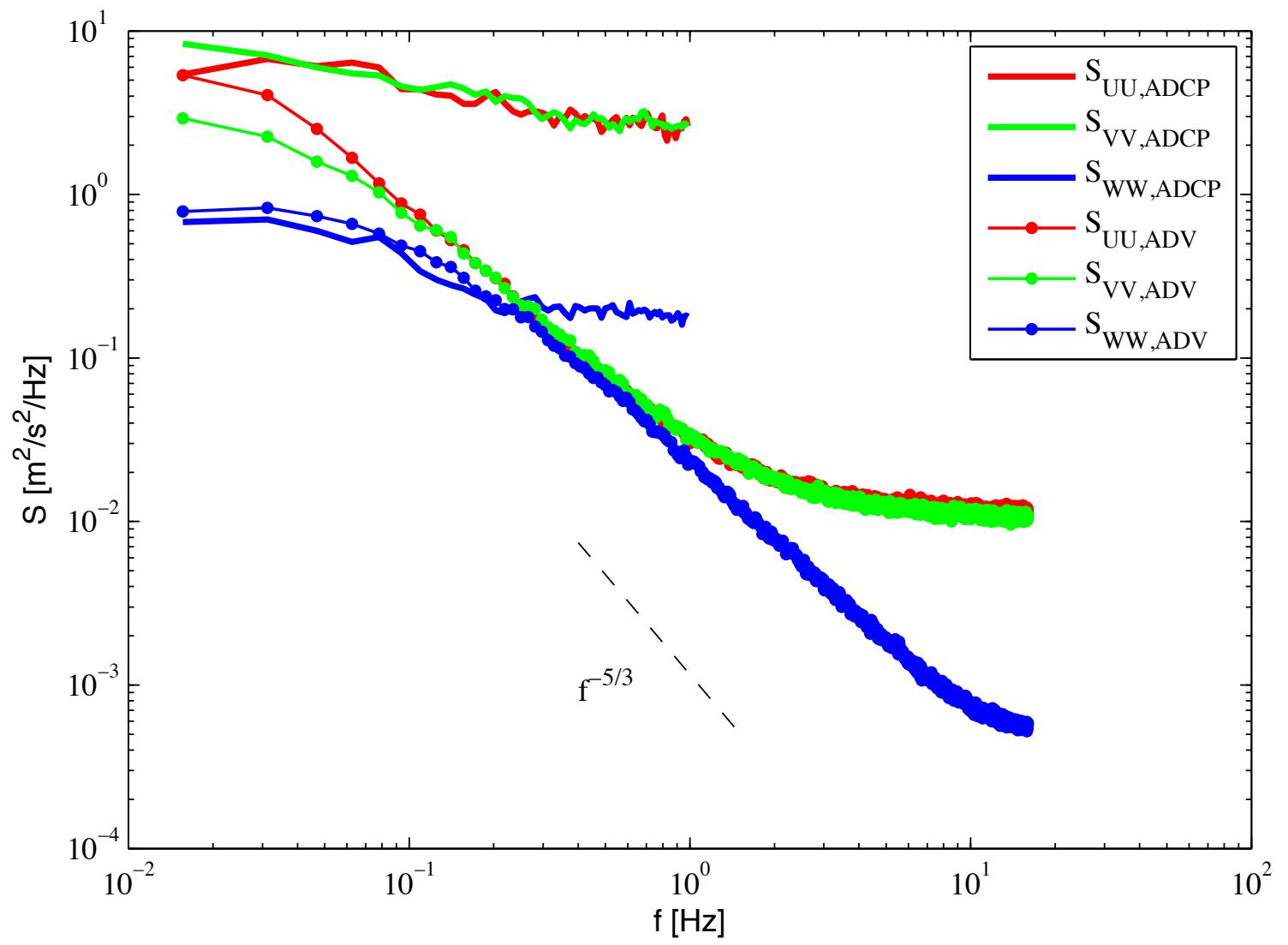

Figure 3.17. Auto-spectral density from ADV and ADCP measurements for non-slack condition. 


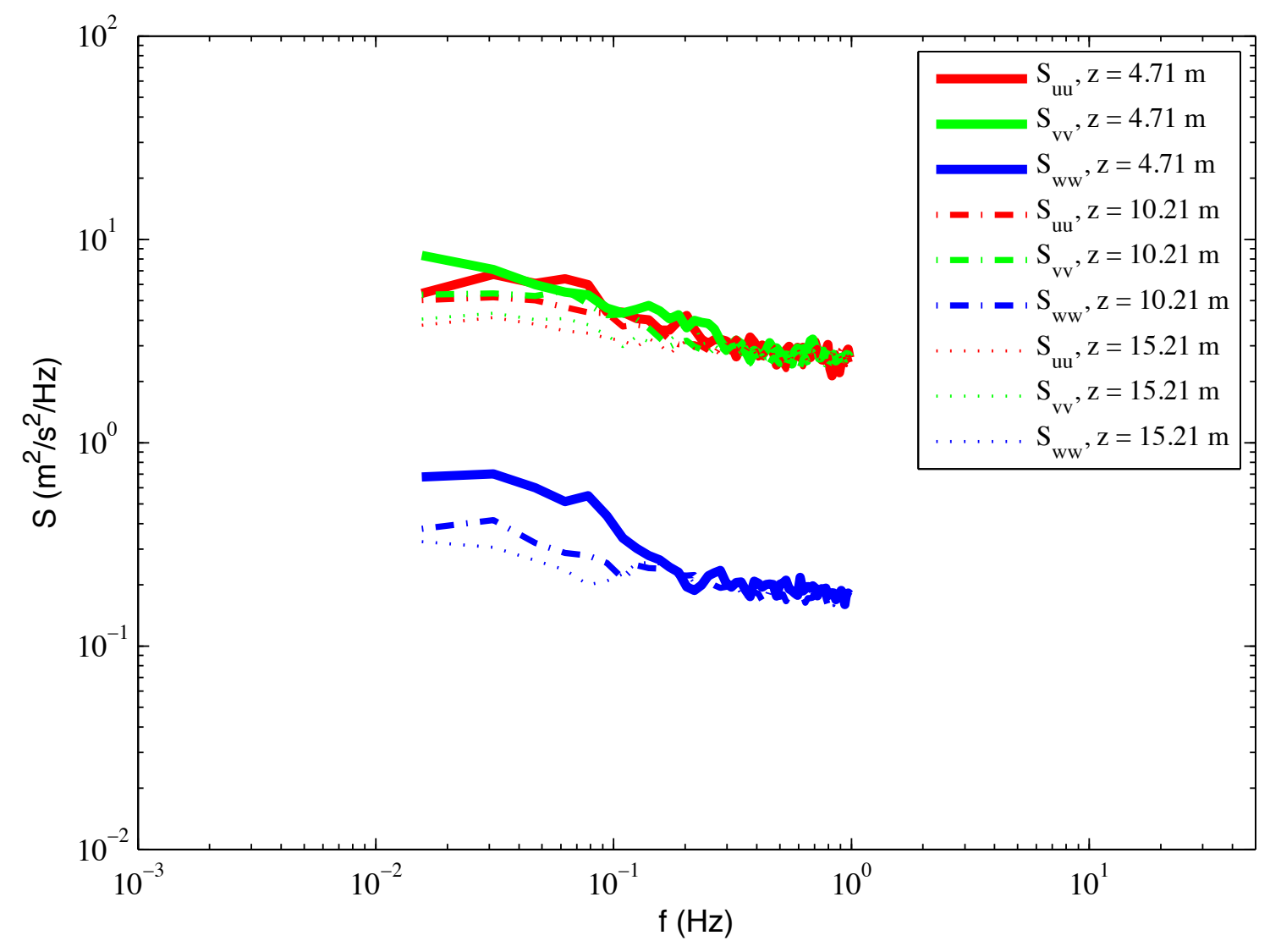

Figure 3.18. Auto-spectral density from ADCP measurements for non-slack condition at different heights $\mathrm{z}=4.21,10.21$ and $15.21 \mathrm{~m}$.
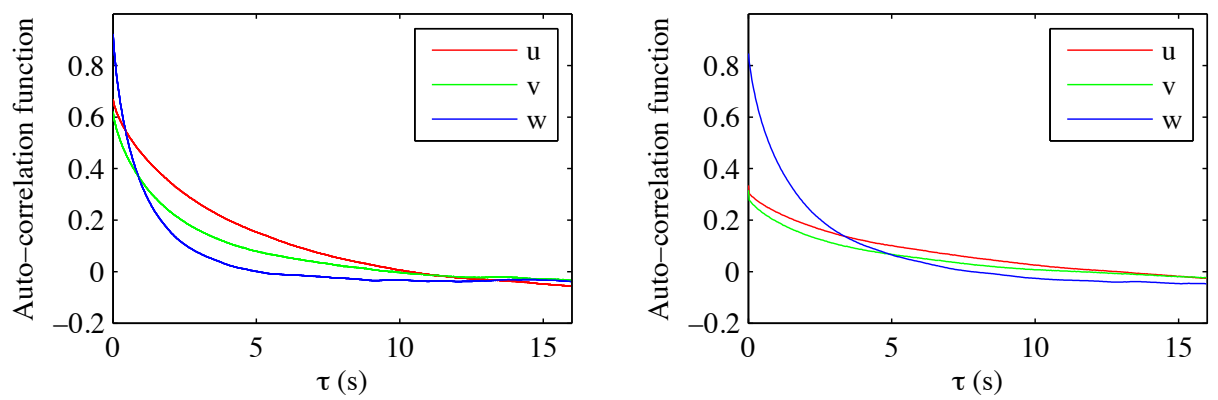

Figure 3.19. Auto-correlation function: (a) non-slack tidal condition, and (b) slack tidal condition. 


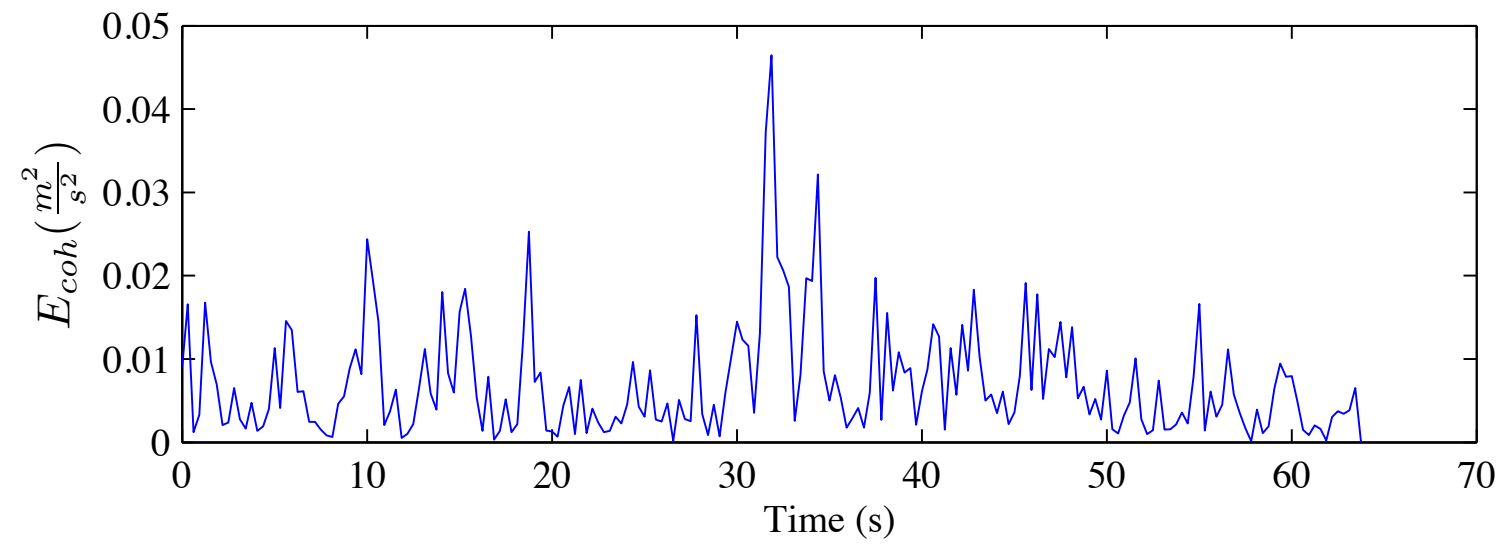

(a) Coherent TKE

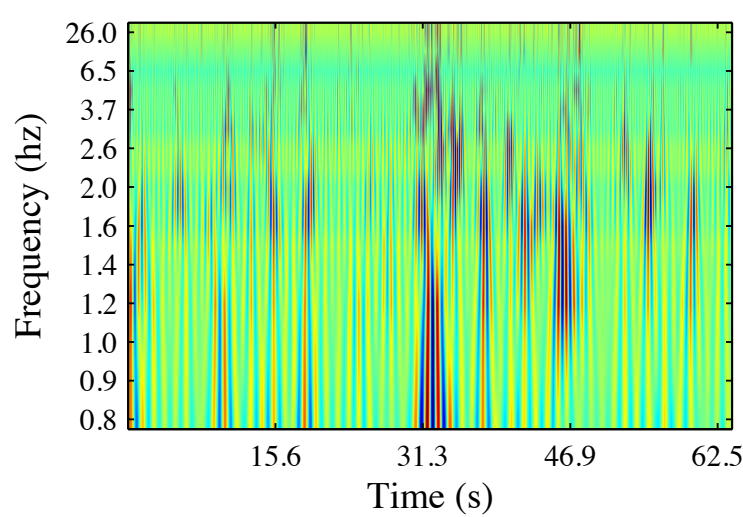

(b) Wavelet

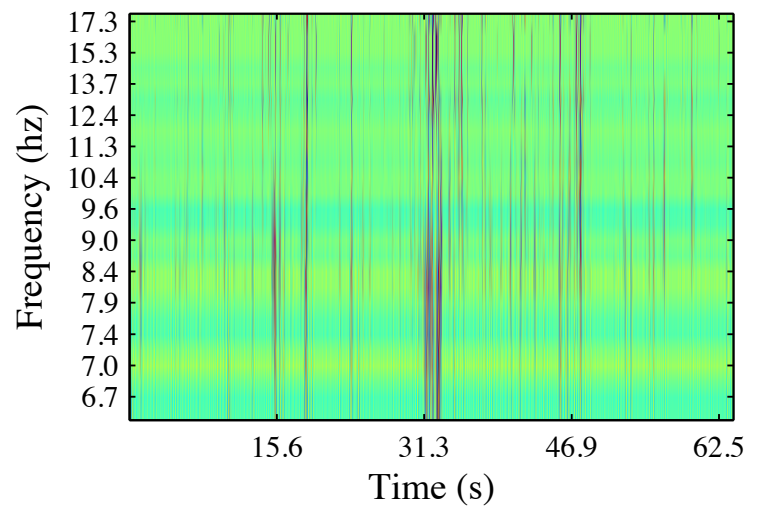

(c) Zoomed in wavelet

Figure 3.20. (a) Coherent Turbulent Kinetic Energy $\left(E_{c o h}\right)$ for a ADV burst, (b) temporalfrequency spectral decomposition of $E_{c o h}$, and (c) Higher frequency component of temporal-frequency spectral decomposition of $E_{c o h}$. 


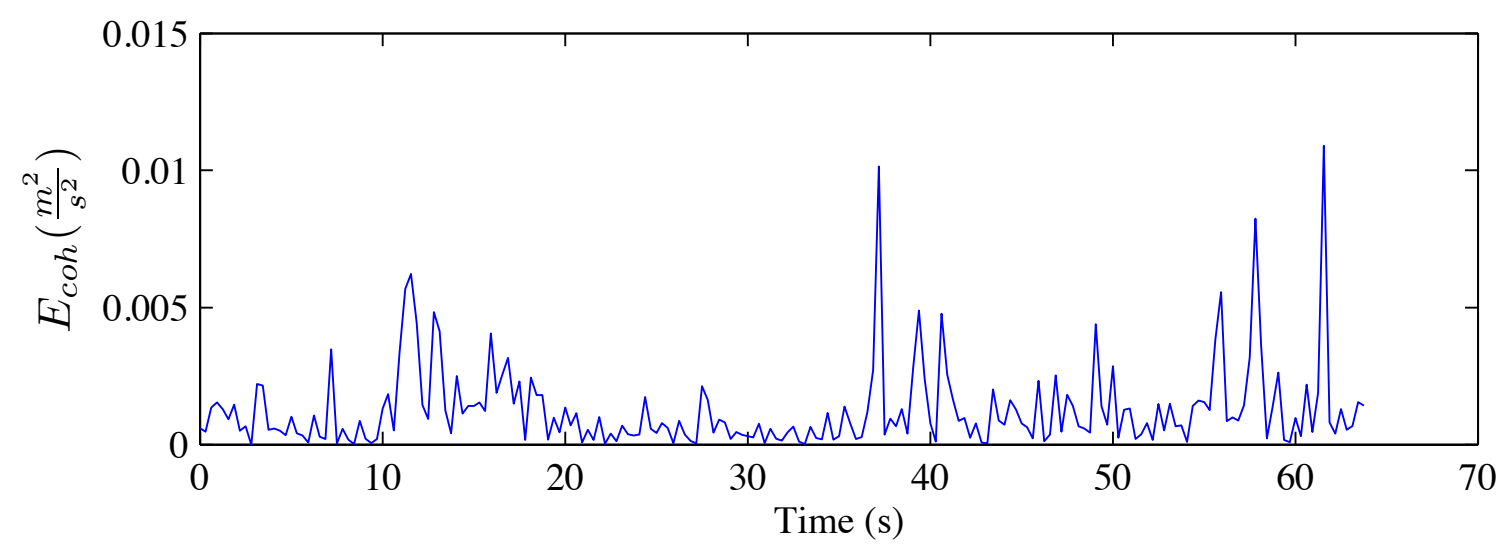

(a) Coherent TKE

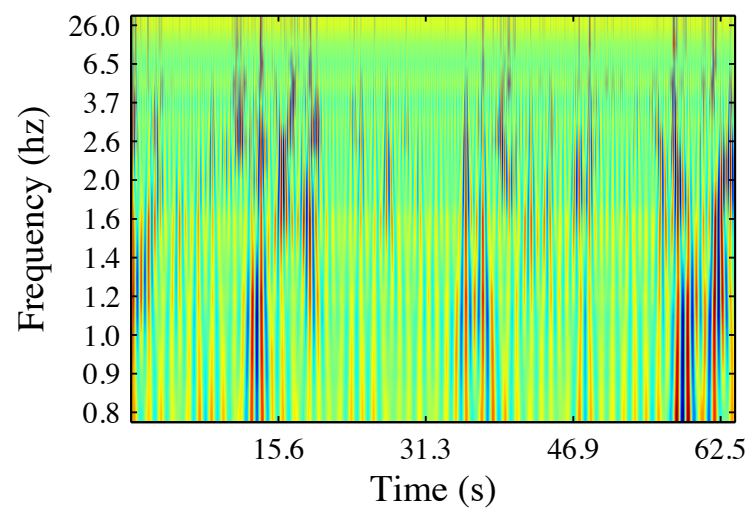

(b) Wavelet

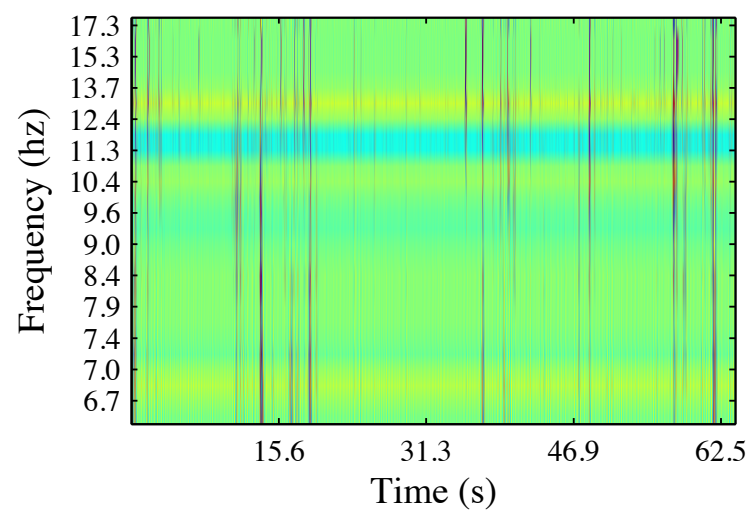

(c) Zoomed in wavelet

Figure 3.21. (a) Coherent Turbulent Kinetic Energy $\left(E_{c o h}\right)$ for a ADV burst, (b) temporalfrequency spectral decomposition of $E_{c o h}$, and (c) Higher frequency component of temporal-frequency spectral decomposition of $E_{c o h}$. 



\subsection{Discussion and conclusion}

The measurements at the Marrowstone Island site in Puget Sound, WA were performed to quantify the site turbulence characteristics for design and installation of MHK devices. For this study, single point velocity measurements and velocity profile measurements were performed using ADV and ADCP respectively. Furthermore, CTD measurements were also performed to understand the flow conditions. The CTD measurements showed that the Marrowstone Island site has characteristics that are typical of an estuary, where a variation in salinity and temperature can be observed during different periods in the tidal cycle, as well as due to seasonal variations.

The ADV measurements were performed close to the base height of MHK devices (i. e. 4.6 $\mathrm{m}$ above seabed). These measurements showed tidal variation in velocities with maximum peak velocity between $1.0-1.5 \mathrm{~m} / \mathrm{s}$ and a dominant flow direction, showing suitability of the Marrowstone Island site for MHK device installations. Furthermore, the velocity profiles and fluctuations both showed dependence on tidal variations, therefore these tidal variations should be kept in mind for design and operation of MHK devices. Finally, the spectrum results from the ADV measurements showed that flow is fully developed turbulent flow with $-5 / 3$ slope of the inertial sub-range portion of spectra.

The ADCP measurements provided a velocity profile from $2.6 \mathrm{~m}$ above the seabed up to the surface. These measurements also showed tidal variations in the velocity profile. However, it is observed that for the slack period, the velocity profile was almost linear, while for the non-slack period, the velocity profile matched a power-law distribution.

In these study, ADCP and ADV were used, and both these instrument have their limitations. ADV was capable of providing data at high temporal resolution but it can perform measurements at a single point only. ADCP was capable of providing the velocity profile but had low temporal resolution. It was also observed that ADCP measurements had significantly higher noise as compared to ADV measurements. Since both these instruments have noise in their measurements, care should be taken while interpreting and analyzing measurements from both these instruments.

The wavelet analysis of coherent turbulent kinetic energy provided information about the energy content of various frequencies at each time step. These measurements showed the presence of energy at higher frequencies which may adversely affect the MHK devices leading to structural failures similar to those observed in the wind turbines. 



\subsection{Future work}

In order to quantify the flow conditions in detail at the Marrowstone Island site, high temporal resolution measurements at various depths are required. For this purpose, a tentative experimental setup is being proposed for FY-2011, a schematic is shown in figure 5.1. This tentative proposed setup will have several ADV at different heights which will provide height-temporal data, and ADCP at the bottom to obtain the whole velocity profile. The ADVs and the ADCP will be deployed using a mooring line instead of a tripod instrument mount, as shown in the tentative schematic setup. This mooring will have the ability to add the ADV at different heights and will be easy to modify and deploy as compared to the existing tripod. Furthermore, lesson learned from FY-2010 experiments will help in designing the experiments focused on capturing turbulence at flood and ebb cycles. A tentative plan for FY-2011 experiments is given in Table 5.1 .

Table 5.1. Tentative Experiments to be performed for FY-2011.

\begin{tabular}{|c|c|c|c|c|}
\hline Measurement & Sample Duration & Sampling frequency & When to sample & Mounting position \\
\hline Current profile & 200 Samples & $2 \mathrm{~Hz}$ & Slack tide & Bottom \\
Current point & 30 minutes & $20 \mathrm{~Hz}$ & Slack tide & Hub height or multi point \\
Temperature profile & 30 minutes & $1 \mathrm{~Hz}$ & Slack tide & Multi-point through water column \\
Salinity profile & 30 minutes & $1 \mathrm{~Hz}$ & Slack tide & Multi-point through water column \\
\hline Current profile & 200 Samples & $2 \mathrm{~Hz}$ & Flood tide & Bottom \\
Current point & 2.5 hours & $20 \mathrm{~Hz}$ & Flood tide & Hub height or multi point \\
Temperature profile & 2.5 hours & $1 \mathrm{~Hz}$ & Flood tide & Multi-point through water column \\
Salinity profile & 2.5 hours & $1 \mathrm{~Hz}$ & Flood tide & Multi-point through water column \\
\hline Current profile & 200 Samples & $2 \mathrm{~Hz}$ & Ebb tide & Bottom \\
Current point & 2.5 hours & $20 \mathrm{~Hz}$ & Ebb tide & Hub height or multi point \\
Temperature profile & 2.5 hours & $1 \mathrm{~Hz}$ & Ebb tide & Multi-point through water column \\
Salinity profile & 2.5 hours & $1 \mathrm{~Hz}$ & Ebb tide & Multi-point through water column \\
\hline
\end{tabular}




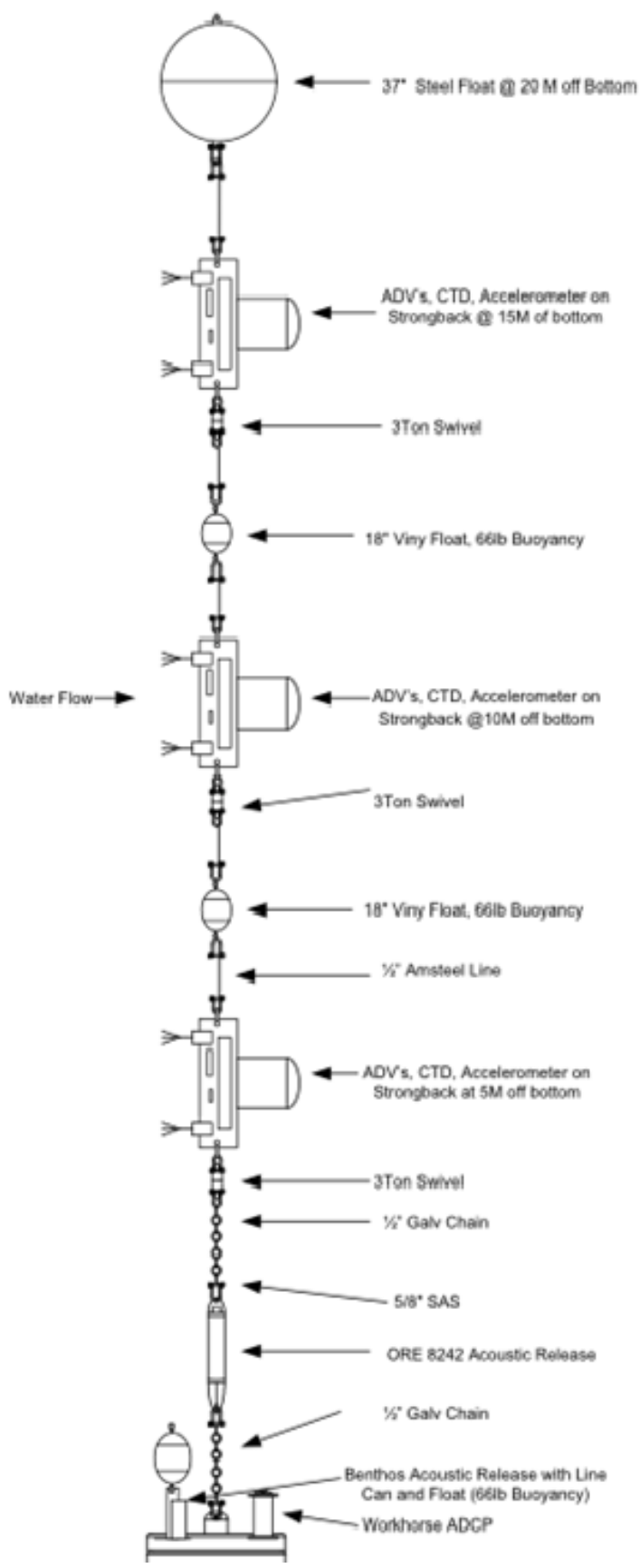

Figure 5.1. Schematic of tentative deployment mooring for FY-2011. 


\subsection{References}

Elgar S and B Raubenheimer. 2001. "Current meter performance in the surf zone." Journal of atmospheric and oceanic technology 18:1735-1745.

Elgar S, B Raubenheimer, and RT Guza. 2005. "Quality control of acoustic doppler velocimetry data in the surfzone." Measurement science technolgy 16:1889-1893.

Garcia CM, MI Cantero, Y Nino, and MH Garcia. 2005. "Turbulence measurements with acoustic doppler velocimeters.” Journal of Hydraulic engineering pp. 1062-1073.

Goring DG and VI Nikora. 2002. "Despiking acoustic doppler velocimeter data." Journal of Hydraulic engineering pp. 117-126.

Kelley ND, BJ Jonkman, GN Scott, JT Bialasiewicz, and LS Redmond. 2005. "Impact of Coherent Turbulence on Wind Turbine Aeroelastic Response and Its Simulation." NREL/CP500-38074 pp. 1884-2010.

Kelley ND and RM Osgood. 2000. "Using Time-Frequency and wavelet analysis to assess turbulence/rotot interactions." 19th American Society of Mechanical Engineers Wind Energy Symposium.

Lane SN, PM Biron, KF Bradbrook, JB Butler, JH Chandler, MD Crowell, and SJ Mclelland. 1998. "Three-dimensional measurement of river channel flow processes using acoustic doppler velocimetry." Eart surface procesesses and landforms 23:1247-1267.

Li Y, N Kelley, B Jonkman, JA Colby, R Thresher, and S Hughes. 2010. "Inflow measurement in a tidal strait for deploying tidal current turbines- Lesson, opportunity and challenges." In Proceedings of OMAE 2010.

Thomson J, B Polagye, M Richmond, and V Durgesh. 2010. "Quantifying turbulence for tidal power applications.” Oceans 2010, MTS/IEEE.

Voulgaris G and JH Trowbridge. 1997. "Evaluation of Acoustic Doppler Velocimentr (ADV) for turbulence measurements." Journal of Atmospheric and Oceanic Technology 15:272-289. 



\subsection{Appendix}

List of all the measurements performed and test conditions:

Table 7.1. Sampling design for all the measurements performed for this study.

\begin{tabular}{|c|c|c|c|c|}
\hline & Sampling frequency & Deployment period & Sampling scheme & Data format \\
\hline ADCP & $2 \mathrm{~Hz}$ & 2 weeks & 64 s every half an hour & Binary file \\
ADV & $32 \mathrm{~Hz}$ & 2 weeks & 64 s every 10 minutes & Binary file \\
CTD & $1 / 30 \mathrm{~Hz}$ & 2 weeks & continuous & ASCII \\
Accelerometer & $1 \mathrm{~Hz}$ & first six hours & continuous & ASCII \\
\hline
\end{tabular}

Typical data post-processing steps for ADCP measurements

1. Converting binary data to ASCII format using in-house developed Matlab script.

2. Performing quality control on the ASCII data. Quality control steps are provided in section 3.1.

3. Converting the beam coordinate velocity data to ENU coordinate velocity data.

Typical data post-processing steps for ADV measurements

1. Converting binary data to ASCII format using Nortek Vector software.

2. Performing quality control on the ASCII data. Quality control steps are provided in section 3.1.

3. Converting the instrument coordinate velocity data to ENU coordinate velocity data using information from sensors data file.

\subsection{Data folder structure}

The data acquired during the FY-2010 experiments were send to NREL on their request. The data were assembled and sorted out as:

\subsubsection{ADCP}

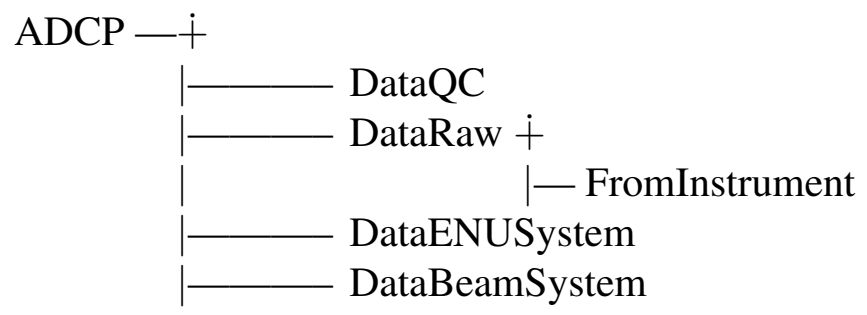




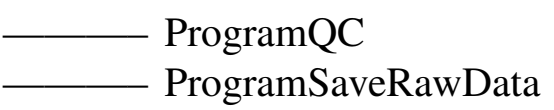

\section{DataQC}

Contains mat file format on which quality control steps has been performed. This mat file contain information of velocities in beam coordinate, time, depth, horizontal velocity and direction. DataRaw

Contain raw data from the ADCP instrument in binary format in a sub-folder FromInstrument. DataENUSystem

Contains a mat file. This mat file was created from WinADCP export function. This matfile contains velocities data in ENU coordinate system.

DataBeamSystem

Contains a mat file. This mat file was created from in-house Matlab script (SaveRawData) function. This matfile contains velocities data in beam coordinate system for quality control purpose.

PorgamQC

This folder contains Matlab script: showing the steps used in QC processing and finally saves quality control steps data in DataQC folder.

\subsubsection{ADV}

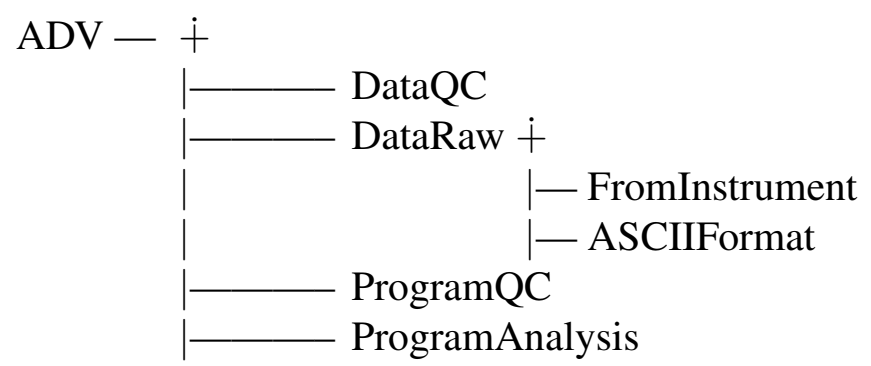

\section{DataQC}

Contain mat file format data. Each individual file is for particular burst. These data is stored after quality control procedure.

\section{DataRaw}

Contain raw data from the ADV instrument in binary format. stored in folder (FromInstrument). This data is converted to ASCII format using Nortek Vector software, and stored in folder (ASCIIFormat)

ProgramQC

This folder contains Matlab script - showing the steps used in quality control processing.

ProgramAnalysis

A simple spectral calculation implementation in Matlab script. 


\subsection{CTD}

The data acquired from CTD experiments were stored in the folder CTD because data was in ASCII format no further processing was necessary. 



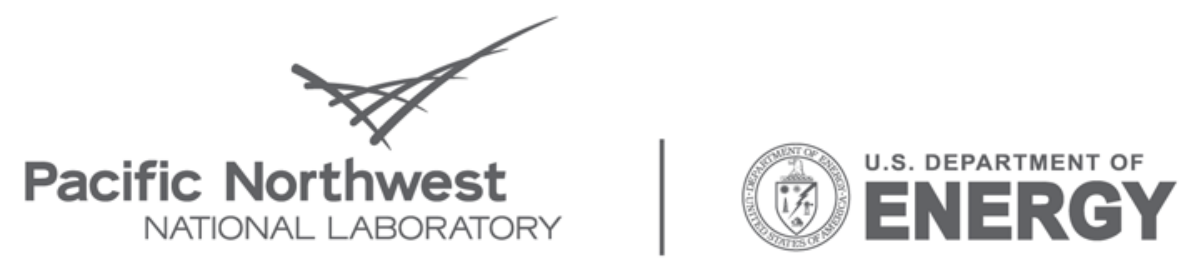

Proudly Operated by Battelle Since 1965

902 Battelle Boulevard

P.O. Box 999

Richland, WA 99352

1-888-375-PNNL (7665)

www.pnl.gov 